NIST Special Publication 1218

\title{
ROAD MAPPING WORKSHOP REPORT ON OVERCOMING BARRIERS TO ADOPTION OF COMPOSITES IN SUSTAINABLE INFRASTRUCTURE
}

Richard Sheridan, Jeffrey W. Gilman, John P. Busel, Dave Hartman, Gale Holmes, Daniel Coughlin, Paul Kelley, William R. O’Donnell, Antonio Nanni, Dustin Troutman, Robert W. Harris, Jim Gutierrez, Charles Bakis, Scott Holmes, Robert Moser, Ellen Lackey, Jim Fekete, Stephanie Watson, Jae-Hyun Kim, Aaron Forster, Ajay Krishnamurthy, Bharath Natarajan

This publication is available free of charge from: https://doi.org/10.6028/NIST.SP.1218

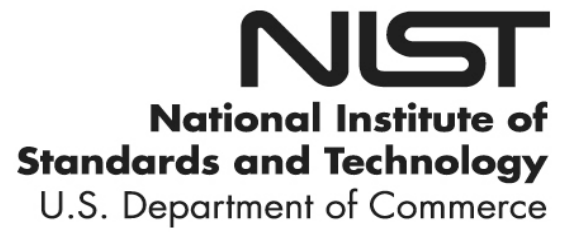


NIST Special Publication 1218

\title{
ROAD MAPPING WORKSHOP REPORT \\ ON \\ OVERCOMING BARRIERS TO ADOPTION OF COMPOSITES IN SUSTAINABLE INFRASTRUCTURE
}

\author{
Richard Sheridan \\ Northwestern University \\ John P. Busel, Daniel Coughlin \\ American Composites \\ Manufacturers Association \\ Jeffrey Gilman, Gale Holmes, James Fekete, \\ Stephanie Watson, Jae-Hyun Kim, Aaron Forster, \\ Ajay Krishnamurthy, Bharath Natarajan \\ National Institute of Standards and Technology \\ Dave Hartman \\ Owens Corning \\ Paul Kelley \\ Simon, Gumpertz, \& Heger, Inc. \\ Antonio Nanni \\ University of Miami \\ Ellen Lackey \\ University of Mississippi
}

\author{
William R. O’Donnell \\ DeSimone Consulting Engineers \\ Dustin Troutman \\ Creative Pultrusions, Inc. \\ Robert W. Harris \\ National Rural Electric Cooperative Association \\ Jim Gutierrez \\ California Department of Transportation \\ Charles Bakis \\ Penn State University \\ Scott Holmes \\ Highland Composites \\ Robert Moser \\ US Army Engineer Research \\ and Development Center
}

This publication is available free of charge from:

https://doi.org/10.6028/NIST.SP.1218

December 2017

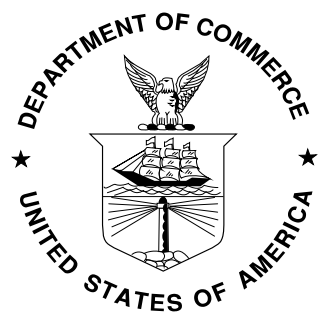

U.S. Department of Commerce Wilbur L. Ross, Jr., Secretary

National Institute of Standards and Technology Walter G. Copan, NIST Director and Under Secretary of Commerce for Standards and Technology 
Certain commercial entities, equipment, or materials may be identified in this document in order to describe an experimental procedure or concept adequately. Such identification is not intended to imply recommendation or endorsement by the National Institute of Standards and Technology, nor is it intended to imply that the entities, materials, or equipment are necessarily the best available for the purpose.

National Institute of Standards and Technology Special Publication 1218 Natl. Inst. Stand. Technol. Spec. Publ. 1218, 47 pages (December 2017)

CODEN: NSPUE2

This publication is available free of charge from: https://doi.org/10.6028/NIST.SP.1218 


\section{Executive Summary}

The February 2017 "Road Mapping Workshop on Overcoming Barriers to Adoption of Composites in Sustainable Infrastructure" brought together designers, engineers, manufacturers, researchers, owners and end-users to identify barriers and potential solutions. Fiber reinforced polymer (FRP) composite products produced in the US offer durable, sustainable, and cost-effective solutions in a variety of infrastructure applications as diverse as dams, bridges, highways, railroads, harbors and waterfront structures, utility poles, and buildings. The overall goal of the workshop was to identify the cross-cutting barriers that must be overcome to enable the adoption of world-leading US FRP composite technology, thereby saving construction costs, and creating a durable $21^{\text {st }}$ century infrastructure that supports economic growth. The workshop was a seminal event; it was the first time that such a complete cross section of interests was assembled to address the specific issue of enabling adoption of FRP composites in infrastructure. The meeting identified three activities (Durability Testing, Design Data Clearinghouse, and Training and Education) that, if enacted, will facilitate wider adoption of FRP composites technology that is potentially more reliable, durable, and costeffective than current solutions. The workshop resulted in a roadmap for addressing barriers to the adoption of FRP composites in infrastructure.

Durability Testing: While FRP composites are highly durable and have been used in many applications for over 50 years, other materials, such as steel, wood, and aluminum, have been in widespread use for much longer. The FRP composite products last longer in corrosive environments than these other materials. For example, many of the FRP composite utility poles installed in the 1960s are still in use today, as compared to wood poles that may, in certain harsh environments, require repair or replacement every 25 years to 40 years due to rot, pest damage, and other degradation mechanisms. ${ }^{1}$ Over the last 50 years there have been many improvements in FRP composite resin, reinforcements, and processing. Consequently, for these new, advanced materials there is limited real-time aging data. Therefore, to reduce excessive design safety factors and maximize weight-savings, accelerated testing is necessary for the adoption of FRP composites used in long-term structural applications.

The workshop participants recommended the development of durability standards, as well as predictive models and data to support those standards. Specifically, a five-year program is recommended to establish testbeds, gather data, and develop models that would result in reliable design tools. The resulting tools would then become widely available to the FRP composites industry, end-users, engineers, architects, and designers through an on-line dataportal. The workshop participants emphasized that industry involvement was vitally important to ensure that the durability standards be commercially relevant.

Design Data Clearinghouse: Many FRP composites manufacturers are already designing, manufacturing, and deploying highly successful products across a broad range of infrastructure applications. These companies have information such as design guides and reliable data tables. Some of this design data is publicly available and developed for specific applications. The participants collectively identified the need for a "clearinghouse" to gather, curate, and disseminate this information for infrastructure applications. They envisioned that this project would provide valuable existing data in the near-term, followed with new data being published continuously every year. After three years, the program could be evaluated to see what additional work might be needed. 
The combination of these two critical activities addresses both long-term (Durability Testing) and short-term (Design Data Clearinghouse) needs. Implementation of these two proposed projects will generate specific and measurable benefits within the first year. These efforts will continuously feed Education and Training materials into university or industrial curricula used in FRP composites training and certification programs. This approach, if adopted, will enable high-tech job creation in the growing FRP composites sector in the US, while at the same time creating a cost-effective and durable $21^{\text {st }}$ century infrastructure to enhance future economic growth.

\section{Key words}

Composites; barriers; design data; durability testing; infrastructure; road map; sustainable. 


\section{Table of Contents}

1. Introduction .............................................................................................................................. 1

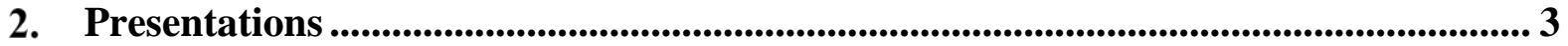

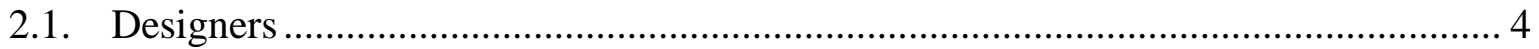

2.1.1. DeSimone ................................................................................................... 4

2.1.2. Simpson, Gumpertz, \& Heger Inc. ………………………………………..... 5

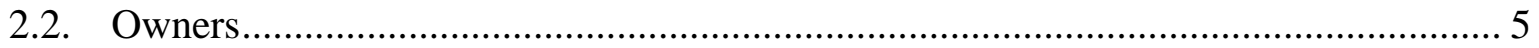

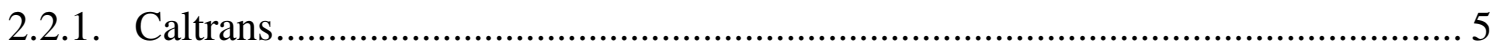

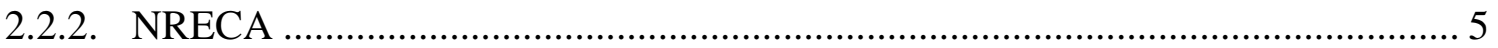

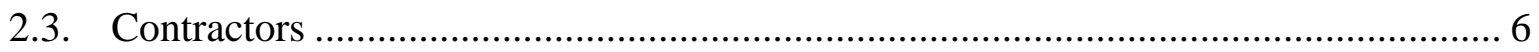

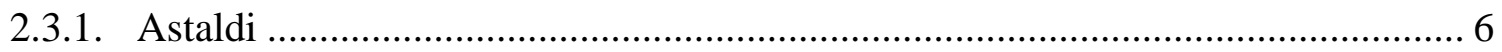

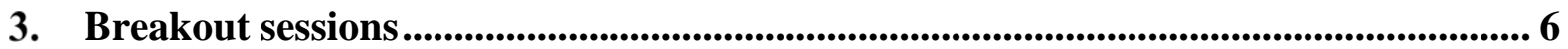

3.1. Breakout Session 1: New Construction ............................................................ 6

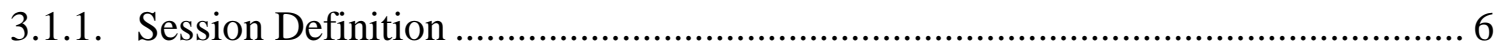

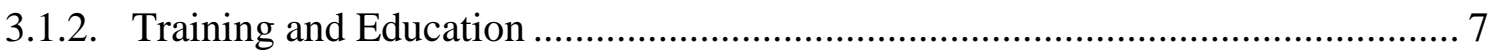

3.1.3. Codes, Specifications, and Standards .............................................................. 7

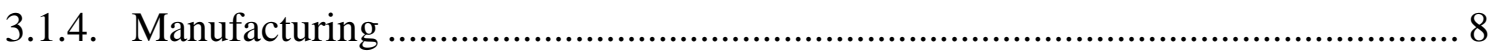

3.1.5. Overcoming the Top Barriers..................................................................... 8

3.2. Breakout Session 2: Repair/Retrofit Construction ................................................... 8

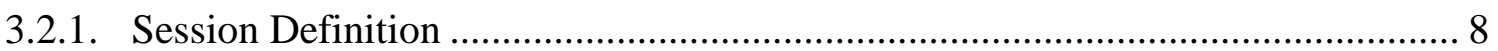

3.2.2. Durability and Service Life ....................................................................... 9

3.2.3. Training and Education .............................................................................. 9

3.2.4. Codes, Specifications, and Standards ............................................................ 9

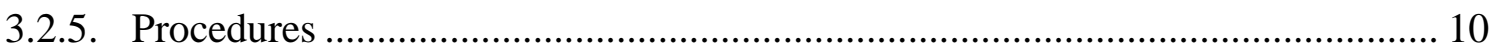

3.2.6. Quality Control.......................................................................................... 10

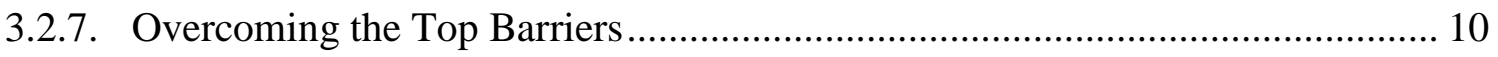

3.3. Breakout Session 3: Stand-Alone Composites ........................................................ 10

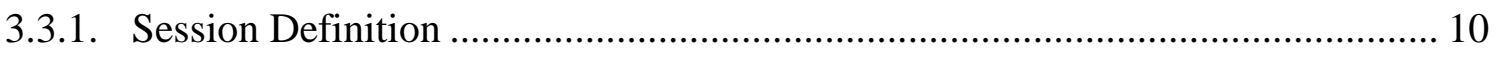

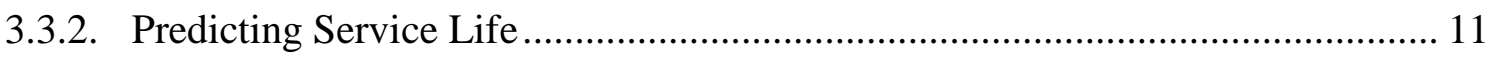

3.3.3. Codes, Specifications, and Standards ............................................................. 12

3.3.4. First-cost Paradigm......................................................................................... 12

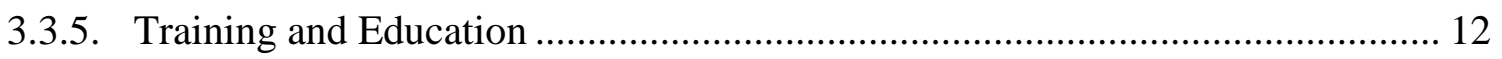

3.3.6. Overcoming the Top Barriers............................................................................ 12 


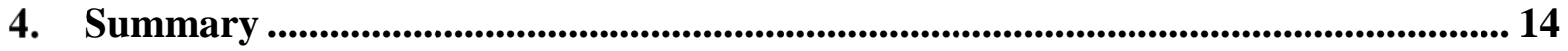

4.1. Barriers to adoption of composites in infrastructure …………………………….... 14

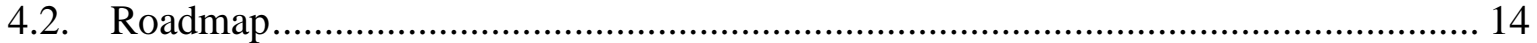

4.3. Durability Testing........................................................................................... 15

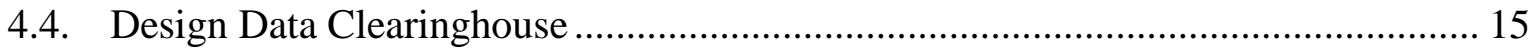

4.5. Training and Education .................................................................................. 16

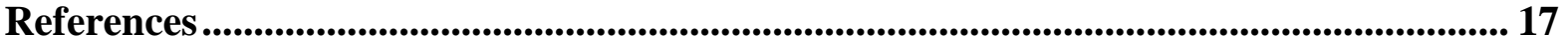

5. Appendix A: Presentations ................................................................................... 18

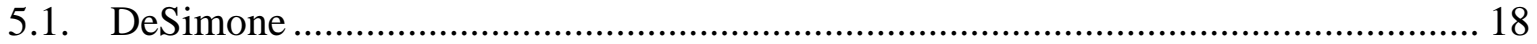

5.2. Simpson, Gumpertz, \& Heger Inc. ……………............................................. 22

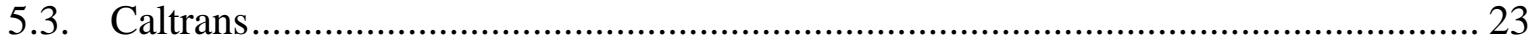

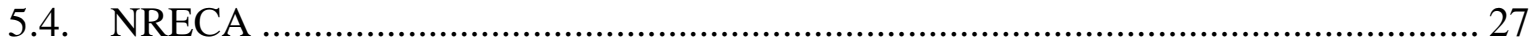

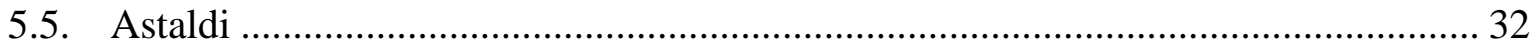

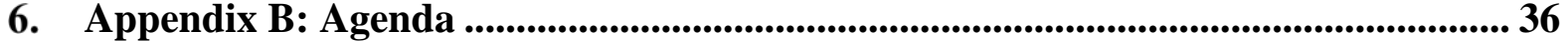

7. Appendix C: Attendees ..................................................................................... 38

8. Appendix D: Additional Material .......................................................................... 39

\section{List of Tables}

Table 1: Matrix of cross-cutting barriers identified by each breakout group.......................... 14

\section{List of Figures}

Fig. 1: Typical FRP cooling tower. Courtesy Creative Pultrusions, Inc. ……………............... 1 Fig. 2: FRP cantilever pedestrian walkway (https://www.compositeadvantage.com/blog/walk-this-way-the-cantilever-sidewalk) ............ 2 Fig. 3: Tunnel boring machine breaking through a GFRP-reinforced "Soft Eye" wall, saving time and cost on rebar removal. Courtesy Astaldi Construction Corporation............................ 3 Fig. 4: Recommended framework for the FRP community. Attention to certification, design, and maintenance provides durability and cost effectiveness is necessary for sustainability. Courtesy Owens Corning.

Fig. 5: Preliminary Roadmap designed during the workshop. This roadmap captures the nine basic efforts (center-section) that need to be completed to overcome the top three barriers (left-side) and achieve the three critical outcomes (right-side). Each effort may result in a workstream with multiple tasks and overlapping concerns. 


\section{Glossary}

$\begin{array}{ll}\text { ASCE } & \text { American Society of Civil Engineers } \\ \text { AASHTO } & \text { American Association of State Highway and Transportation Officials } \\ \text { ACI } & \text { American Concrete Institute } \\ \text { ACMA } & \text { American Composites Manufacturers Association } \\ \text { ASCE } & \text { American Society of Civil Engineers } \\ \text { ASME } & \text { American Society of Mechanical Engineers } \\ \text { ASTM } & \text { ASTM International, formerly American Society for Testing and Materials } \\ \text { Caltrans } & \text { California Department of Transportation } \\ \text { CFRP } & \text { Carbon Fiber Reinforced Polymer } \\ \text { FGMC } & \text { Fiberglass Grating Manufacturers Council } \\ \text { CRSI } & \text { Concrete Reinforcing Steel Institute } \\ \text { FRP } & \text { Fiber Reinforced Polymer } \\ \text { GFRP } & \text { Glass Fiber Reinforced Polymer } \\ \text { NCAMP } & \text { National Center for Advanced Materials Performance } \\ \text { NIST } & \text { National Institute of Standards and Technology } \\ \text { NRECA } & \text { National Rural Electric Cooperative Association } \\ \text { NSM } & \text { Near-Surface Mounted } \\ \text { ORNL } & \text { Oak Ridge National Laboratory } \\ \text { PCI } & \text { Precast Concrete Institute } \\ \text { USACE } & \text { United States Army Corps of Engineers } \\ \text { USDOE } & \text { United States Department of Energy } \\ \text { United States Department of Transportation } \\ \text { ASDO }\end{array}$




\section{Introduction}

There is a pressing nationwide need to build, repair, and reconstruct US infrastructure that comprises marine structures, transportation structures like bridges, tunnels, roadways, powergrid structures, dams, pipelines and other civil structures. This is especially true of infrastructure in corrosive and harsh environments. The American Society of Civil Engineers (ASCE) estimates that the current total outlays for infrastructure in the United States are \$250 billion/yr., whereas infrastructure needs across 2016-2025 are estimated at as much as \$460 billion/yr. Federal and State infrastructure agencies must invest at some point in the near future or face severe economic consequences. ${ }^{2}$ Fiber reinforced polymer (FRP) composites are a versatile, sustainable and corrosion-resistant structural material, which could be a key enabler in this process, offering a price-performance tradeoff that could reduce the total outlays necessary compared to those of conventional structural materials. While private and public entities have begun to introduce FRP composites into real-world applications, barriers to the widespread use of these materials in infrastructure continue to exist at all levels, from regulation to fundamental materials science.

Despite these barriers, there are some niche areas in which FRP composites have been successfully deployed. Field erected FRP composite cooling towers have become the norm over the last 25 years. According to Creative Pultrusions, Inc., approximately $70 \%$ of all the cooling towers constructed today are made of FRP. This is because corrosion resistant FRP members maintain their structural integrity while being exposed to corrosive treatment chemicals and salt water.

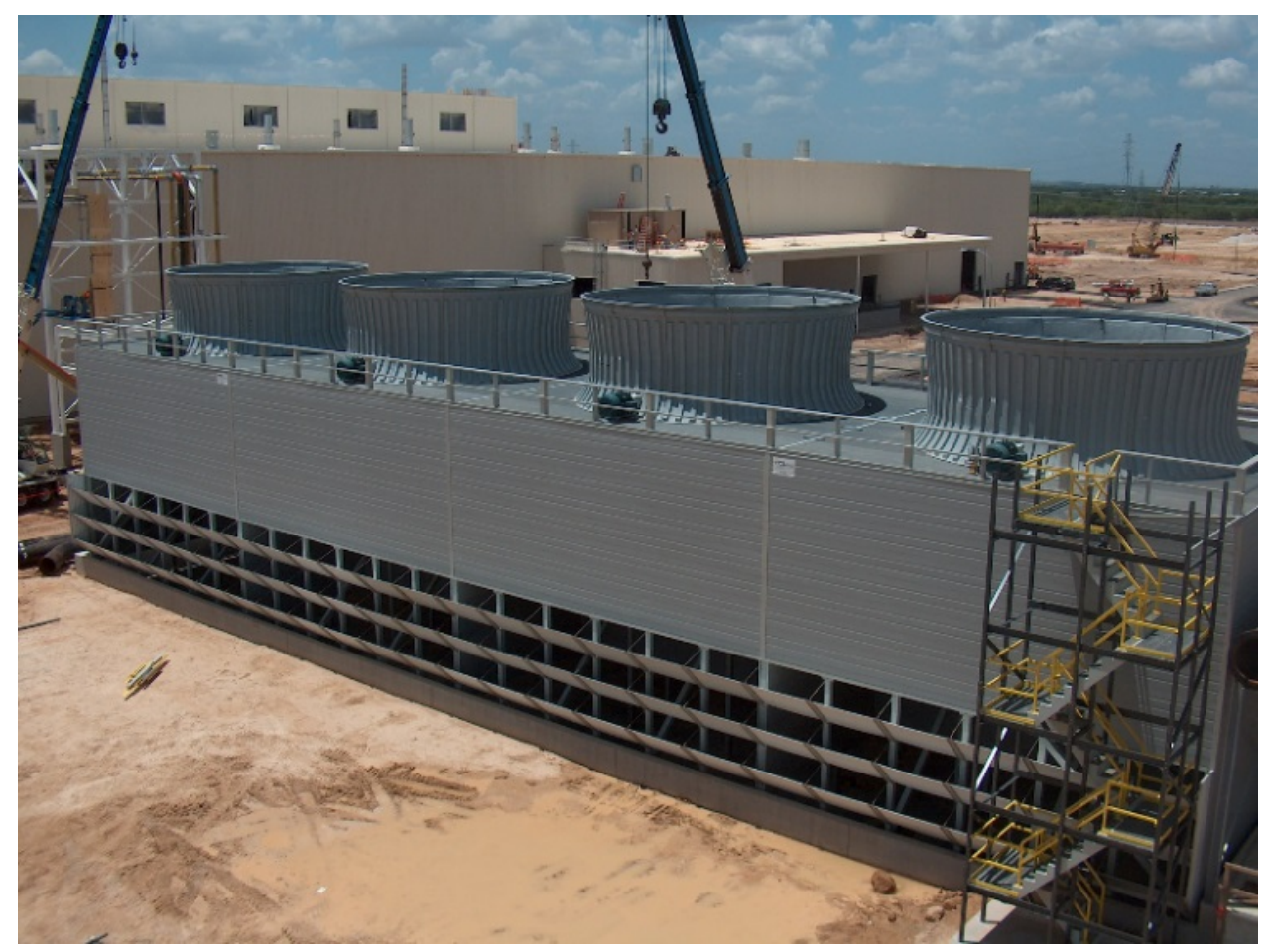

Fig. 1: Typical FRP cooling tower. Courtesy Creative Pultrusions, Inc. 
In addition to excellent corrosion resistance, FRP composites have a high strength-to-weight ratio and less embodied energy. FRP composites are widely used today in both the new construction of bridge decks as well as to retrofit bridge deck panels in existing bridges. In some cases, this has enabled engineers to retrofit bridges with cantilever pedestrian walkways due to the lightweight nature of FRP composites.

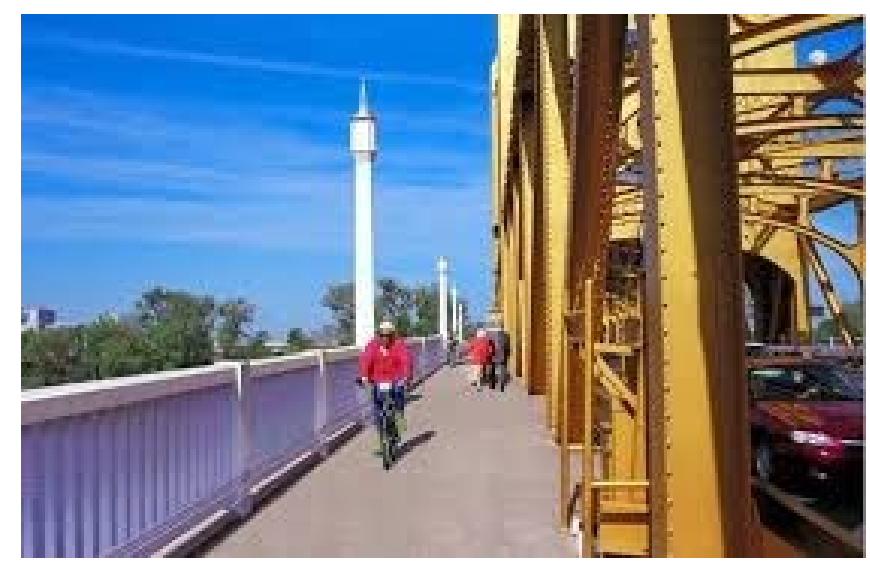

Fig. 2: FRP cantilever pedestrian walkway (https://www.compositeadvantage.com/blog/walk-this-way-the-cantilever-sidewalk)

Low electrical and magnetic conductivity is another key differentiator of FRP composites over traditional rebar structures for applications in hospitals, power plants, and communications structures. Other structural applications may benefit from their low thermal conductivity. Lifecycle cost analysis favors the use of FRP composite materials in many applications. ${ }^{3}$. FRP composite pipes also offer important advantages in the hydrogen economy. Unlike steel, FRP composite pipelines do not corrode or embrittle due to hydrogen gas. ${ }^{4}$

Market share for FRP composites varies widely, depending on the application. Caltrans estimates the market share for Near Surface Mounted (NSM) FRP for strengthening concrete bridge-deck overhangs to be approximately $90 \%$, whereas all-FRP composite bridge decks, and FRP composite prestressed piles and girders, have a market share of less than one percent. Seismic retrofit of columns is performed using FRP strengthening systems through wrappings, although the volume installed with respect to steel column confinement is unknown. Structural strengthening of girders, pier caps and pier walls is another emerging growth areas for FRP composite although the volume used in comparison to conventional materials is currently unknown. According to the American Composites Manufacturers Association, the use of glassFRP (GFRP) rebar is increasing. GFRP rebar has found use in concrete reinforcement in 65 bridges across 27 states in the US, and in over 200 bridges across 4 provinces in Canada. Domestically and internationally, the use of GFRP composite rebar for the reinforcement of the entry or exit, in reinforced concrete walls of tunnel excavations (known as "soft-eyes") is now an accepted practice that has completely replaced the use of steel bars, since GFRP can be cut away more efficiently than steel. 


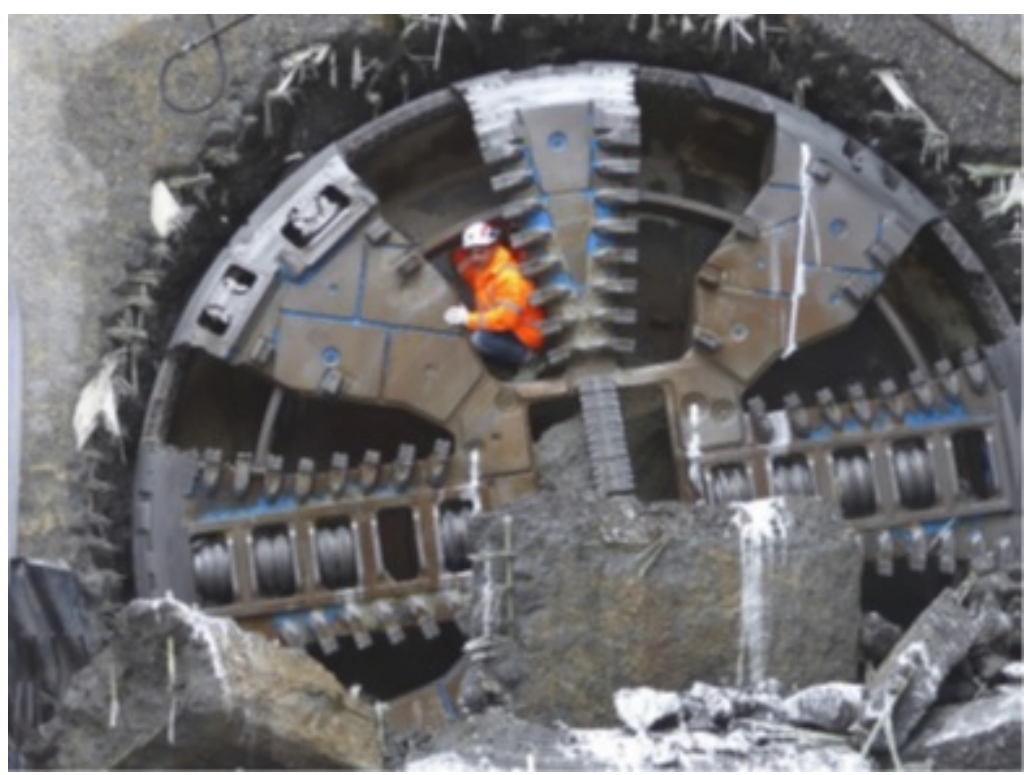

Fig. 3: Tunnel boring machine breaking through a GFRP-reinforced "Soft Eye" wall, saving time and cost on rebar removal. Courtesy Astaldi Construction Corporation.

Clearly, FRP composites address a broad range of needs in many infrastructure applications, and there is potential for significant benefit to be realized if these materials can be adopted more widely. However, as this report documents, a number of issues must be addressed for this to occur.

The goal of the "Road Mapping Workshop on Overcoming Barriers to Adoption of Composites in Sustainable Infrastructure" was to identify the cross-cutting barriers that must be overcome to enable faster commercialization of FRP composites for a more sustainable infrastructure. The workshop was held on February $8^{\text {th }}$ and $9^{\text {th }}, 2017$ at the National Institute of Standards and Technology (NIST) Advanced Measurement Laboratory in Gaithersburg, Maryland. The agenda for the workshop is shown in Appendix B: Agenda. The workshop was a forum for 60 participants (see Appendix C: Attendees) from industry, government, and academia including owners, designers, and contractors - to discuss, in an open and candid forum, the challenges faced in the introduction and use of FRP composite materials for infrastructure applications. The report from the workshop will inform the work of Federal agencies, as well as non-profit technical societies, trade associations, and other stakeholders in the development and adoption of standards, guidelines, and predictive tools for enabling the application of FRP composites in infrastructure. ${ }^{1}$

\section{Presentations}

Keynote speakers at the workshop (see Appendix A: Presentations), who were designers, owners, engineers, and contractors in the infrastructure market, were asked to address the following questions, to help the attendees understand the key issues associated with FRP composite in the infrastructure sector:

\footnotetext{
${ }^{1}$ This publication is intended to capture external perspectives related to NIST standards, measurement, and testing-related efforts. These external perspectives can come from industry, academia, government, and other organizations. This report was prepared as an account of a workshop; it is intended to document external perspectives; and does not represent official NIST positions.
} 
1. Who are you and what do you do (responsibilities) for your organization?

2. What are the 5 biggest challenges you face in your business/organization?

3. What solutions would address those challenges?

4. What experience have you had with FRP composite materials, including but not limited to FRP rebar, decking, repair, utility poles, storage tanks, pilings, dams, earthworks, and cladding?

5. Based on your experience, what are the best applications for FRP composite materials?

6. What are the barriers to adoption of FRP composite materials?

7. What guidelines, standards, technologies, or other developments for FRP composites materials would address these barriers to adoption?

While the technical breadth of the keynote speakers was extremely diverse, representing a broad swath of the Nation's infrastructure portfolio, four key challenges emerged as impediments to the wide spread adoption of FRP composites as standard infrastructure construction materials. These challenges include:

1. There is an overall lack of education and familiarity with FRP composites.

2. There is a need for jurisdictionally uniform design standards to simplify engineering and manage risk.

3. There is a shortage of engineers who understand FRP composites enough to identify and manage risk in new designs.

4. There is a need for a "clearinghouse" to provide easy access to standards, guidelines, and case studies for architects, engineers, and designers.

The discussion around these key challenges was an important part of the breakout sessions following the keynote presentations. It helped to inform the recommendations made in this report. It is encouraging that "new technology" was not one of the top 5 challenges identified by the presenters. The advantages of using FRP composites products are significant and the community does not foresee other disruptive technologies on the horizon that could displace their future importance in infrastructures.

In this next section, we provide a brief technical summary for each of the keynote presentations.

\subsection{Designers}

\subsubsection{DeSimone}

William R. O’Donnell of DeSimone Consulting Engineers outlined the challenges faced by DeSimone designing a resort on reclaimed islands in the Indian Ocean. He described the nearimpossibility of producing high-quality concrete with inherently salt-laden aggregates and poor water quality, stating that existing resorts in this region have significant concrete spalling problems. He explained how use of FRP reinforcing bars removes the concern of protecting steel reinforcing bars with high-quality concrete in a highly corrosive environment. He listed a few of the current optimal applications of CFRP composite materials, including coastal applications using FRP structural bars, where potable water is unavailable for concrete construction, structural enhancement, and structural repair. He identified the following key barriers to adopting FRP composite materials: a lack of familiarity with composites among owners, designers, and contractors, and the initial cost of FRP composite materials. To address 
these barriers, he recommended the following: more FRP composite technical seminars and workshops, including direct presentations by manufacturers to engineers and contractors; initial and long-term cost studies to encourage owner and developer buy-in; publication of unified design standards and specifications for FRP composite materials across jurisdictions; and establishment of a FRP composite material supply chain, that is reliable both in quality and quantity.

\subsubsection{Simpson, Gumpertz, \& Heger Inc.}

Paul Kelley of Simpson, Gumpertz, \& Heger Inc. provided a summary of FRP activities that they have been involved with over the past 15 years. These activities include initial development of guidelines for strengthening existing concrete and masonry elements, seismic strengthening of concrete structures, rehabilitation of large diameter concrete pipes with FRP, and engineering of stand-alone structures like wind turbines made of FRP composites. The main theme of Paul Kelley's presentation was that the development of guidelines is tedious, especially when the focus of the guideline is excessively broad. He described how many features of the ACI guideline and code development process for use of FRP composites in a broad spectrum of applications have not proved as productive as the application-specific content of the American Water Works Association's guidelines for FRP composite reinforcement of pipes.

\subsection{Owners}

\subsubsection{Caltrans}

Jim Gutierrez, of the California Department of Transportation, spoke about the department's wide range of usage of FRP composite materials. Caltrans has been involved in composites research and testing for many years and has implemented composites in a range of applications from seismic retrofit, flexural and shear strengthening of various bridge elements including the NSM method, high load impact repairs, and FRP bridge decks to FRP snap-locking sign structures. Caltrans has implemented a prequalification program with rigorous durability testing requirements for FRP composites used for seismic retrofit and strengthening. They also require random quality control and material testing on FRP strengthening projects. To improve the development of design guidance, adoption of American Association of State Highway and Transportation Officials (AASHTO) guidelines were recommended along with a curated material specification database, which would include all relevant guideline and standards publications.

However, Caltrans faces challenges to realize widespread adoption of FRP composites. Dr. Gutierrez stressed that maintaining quality control in wet lay-up applications is vitally important, which he proposed might be addressed by more extensive review of expectations and experience with installers. Finally, because of: (1) design strength characteristics in wet lay-up applications are highly dependent on the quality of the installation process; (2) the difficulty in obtaining qualified installers, and (3) the issue of other departments of transportation not having the skilled personnel to recognize potential FRP installation problems, Dr. Gutierrez suggested that prequalification requirements be standardized to address these issues.

\subsubsection{NRECA}

Robert Harris, of the National Rural Electric Cooperative Association, gave an overview of the needs of electrical distribution in relation to new construction with FRP composites. Although 
FRP composite poles present some advantages (lightweight, modular, high dielectric strength, low relative permittivity, flexible), the following concerns limit the adoption of this FRP composite technology: (1) impact performance, (2) ultraviolet (UV) degradation, (3) servicelife prediction, and (4) end-of-life disposal. Installers also have a lack of familiarity and expertise with the materials that leads them to favor wood-based solutions. While this problem can be managed effectively for new construction, major storm restoration presents an entirely different situation. The need to bring in many poles and outside crews to restore service as rapidly as possible poses a serious challenge to the use of composites in those circumstances. All distribution line crews are fully trained and equipped to work with wood poles. Currently, introduction of new materials, training, and equipment under emergency circumstances delays restoration of service.

\subsection{Contractors}

\subsubsection{Astaldi}

Antonio Nanni of the University of Miami presented for Sergio Notarianni of Astaldi Construction Corporation. He identified overall expense, beyond the direct cost of FRP composite materials, as a challenge for the adoption of FRP composites. The overall expense includes indirect costs such as lead time and over-procuring for contingencies, additional training and oversight needed to ensure correct placing of the bars in the field, among others. To improve this situation, he recommended focusing on reducing those costs through improvements in logistics, planning, and other training, as well as giving attention to procurement issues that delay construction. He identified the best applications for FRP composites from the perspective of Astaldi as tunnel construction and tunnel linings, light rail transit track beds, and concrete reinforcement in marine and other harsh environments.

\section{Breakout sessions}

Following the presentations, the attendees were divided into three breakout sessions: New Construction, Repair/Retrofit Construction, and Stand-Alone Composites. The groups were charged with identifying the five biggest challenges with using FRP composites in their assigned niche, as well as identifying the individual barriers faced in the adoption of FRP composites considering various factors such as cost, agency buy-in, etc. Each group was asked to name the important stakeholders for their topic area, and the makeup of the teams that could best tackle the top barriers to composite adoption. Across the groups, both cross-cutting and unique barriers and recommendations were identified.

A summary of the discussion, conclusions, and recommendations from each group is presented in the next sections.

\subsection{Breakout Session 1: New Construction}

\subsubsection{Session Definition}

The adoption of FRP composites for new construction represents a paradigm shift for designers, contractors and owners. The participants identified niche applications such as marine structures, bridges, decks, building exteriors, geotechnical works, support units, and pipes as suitable areas for FRP composites use. The driver for the deployment of FRP composites in new construction focused on internal reinforcement for concrete structures (rebar) to overcome the challenge of corrosion. The group identified the top barriers for standalone FRP composite structures: (1) training and education; (2) codes, specifications, and 
standards; and (3) manufacturing. Specific challenges within each barrier category are discussed below.

\subsubsection{Training and Education}

The primary barrier to the successful incorporation of FRP composites for infrastructure applications was decided by consensus of this breakout group to be the current lack of education and workforce training. The first hurdle towards a knowledgeable workforce was agreed to be the lack of FRP composites education in civil engineering, architecture, and architectural engineering programs. Furthermore, the specialized programs that teach FRP composites were found to be incompatible with the licensing requirements of the civil engineering industry.

On a related note, the group concurred that the infrastructure workforce needed to be trained on FRP composites-specific aspects such as handling, installation (including interfacing with tradition construction materials), storage, inspection, safety, and maintenance. This would provide field engineers with the confidence and the willingness to work with FRP composites. With regards to maintenance, the group agreed that currently, inspectors were not sufficiently qualified or knowledgeable in FRP composites for construction. As one participant aptly commented, "Boat builders cannot be inspecting bridges!”

The group also commented on the lack of singular, reliable sources of FRP composites information. FRP composites in general, are perceived to be "risky" materials. It was suggested that access to a centralized knowledge repository on FRP composite design information and case studies might help minimize this perception of risk.

The group also identified that modeling tools for FRP-composite-specific design and development were absent. Additionally, widely used design software were found to be inadequate due to the lack of FRP composites database modules. This is further complicated by the fact that FRP composites display part-specific anisotropy and cannot be modeled as an isotropic material such as steel. This is a fundamental challenge of FRP composites and can only be overcome through education and proper use of modeling tools and methods.

\subsubsection{Codes, Specifications, and Standards}

The group agreed that there were significant variations in material properties between and within suppliers. Participants from the infrastructure sector voiced their discomfort in having to "think too much" prior to procuring FRP composite parts, due to the said variations. In response, there was a strong call for standardization of minimum material performance standards at the constituent and part levels, as is currently being maintained by ASTM for other material classes.

The effect of the FRP composites industry structure on the supply chain was recognized as another key issue. The constituent (fiber, matrix, and filler) manufacturers are large reputable companies with international certification. However, the part manufacturers, who are a vital link in the supply chain, are small fabricators who may lack credibility and sophistication. Due to this, there is a dearth of proven products and precision in the FRP composites market. The group expressed the need to qualify and approve the supply chain by putting in place stringent quality standards, specifications, and inspection protocols. Such an approach could be complimented by a formal certification program by relevant industry organizations. 
The group also identified that many of the current FRP composite components were unnecessarily overdesigned with old and large safety factors due to the lack of familiarity with FRP structure-property relationships over the service life of a structure. This in turn drives up the costs and weight of these components. Furthermore, most design endeavors do not incorporate durability as a design parameter.

\subsubsection{Manufacturing}

The group suggested that a single reliable organization should define metrology that can be used to achieve a clear demonstration of FRP composites performance. This should include standardized methods for conditioning protocols and accelerated testing that mimics environmental aging and durability characteristics. The group re-iterated the need to qualify the supply chain and establish quality assurance and quality control at the part-manufacturer level. The group agreed that the appropriate tools to install FRP composites (and/or interface with existing construction) were lacking. This issue was identified as a key hindrance to the usage of FRP composites in construction. The group recommended that manufacturers maintain an inventory of part-specific accessories (e.g., specialized drill bits and saws) that facilitate installation.

\subsubsection{Overcoming the Top Barriers 3.1.5.1.Training and Education}

The group recommended establishing partnerships between industries, professional societies (ASCE, American Concrete Institute (ACI), etc.) and academic institutions to help educate and familiarize students on the topic of FRP composites. There was also extensive emphasis placed on the need to educate the construction industry and their customers on the advantages and limitations of FRP composites, the key benefit being their excellent durability and lifecycle costs. Furthermore, it was suggested that the easiest way to accelerate adoption of FRP composites would be to identify high-volume applications that hold the highest value for the industry and the customer. There was general agreement that the marketing and communication of FRPs needed to be improved to accomplish FRP composite adoption. The group noted the additional work required the development of database modules and analysis packages in collaboration with software companies, where designs for standard FRP composite parts could be readily accessed from the materials library.

\subsubsection{Codes, Specifications, and Standards}

The group noted that the approved supplier systems that function within the automotive and aerospace industries could be used as templates for adopting material performance standards practices. The group proposed to optimize and standardize FRP composite design, as well as to build validated design software solutions, to reduce overdesign and excessive safety factors. The collaboration of various reputed organizations such as ASTM, ACI, AASHTO, US Army Corps of Engineers, ASME, ASCE, PCI, and USDOT was deemed necessary for the establishment of robust codes, specifications, and standards. Mandating the use of these codes would effectively accelerate innovation for the design, use, and deployment of FRP composites by designers and users, at the cost of potentially limiting innovation by FRP manufacturers.

\subsection{Breakout Session 2: Repair/Retrofit Construction}

\subsubsection{Session Definition}

Typical applications of FRP composites for repair/retrofit discussed during the breakout session included strengthening of bridge structures including columns, girders, pier caps, 
deck overhangs, and barrier walls. Other applications discussed included the following: marine pilings, pipelines, and turbine structures for wind. Seismic flexure/confinement and shear seismic retrofit applications using FRP composites were presented in the whole group discussion, but not specifically discussed in the repair/retrofit breakout group.

Barriers to the wide use of FRP composites were identified during the discussion, and many of the barriers interconnected with each other. For instance, insufficient codes and standards are related to less-defined construction procedures.

The group identified the following top barriers for repair/retrofit construction: (1) durability and service life; (2) training and education; (3) codes, specifications, and standards; (4) procedures; and (5) quality control. Specific challenges within each barrier category are discussed below.

\subsubsection{Durability and Service Life}

Inadequate durability and service life information for FRP composites as a function ultraviolet/moisture, mechanical fatigue/creep, salt spray, freeze/thaw cycling, and temperature exposure were important issues. Validated industry standard models for service life prediction are needed. Appropriate life cycle costs for developing models as well as defining critical model parameters for correct inputs were identified as associated challenges. Access to legacy data (e.g., proprietary and public domain) from various manufacturers and/or actual projects was suggested for validation of models. In addition, a lack of data for fire/high temperature resistance properties of FRP composites was discussed; it is particularly difficult to introduce FRP composite materials into applications subject to fire hazards.

\subsubsection{Training and Education}

Improvement of training and education for proper design and installation of FRP composites is needed. The participants agreed that engineers should understand mechanics of polymers and fiber reinforcements for adopting FRP composites into current structural designs. Continuing education for current engineers whose emphasis has been on conventional concrete and steel structure design was also highlighted as a way to promote use of FRP composites in structural designs.

\subsubsection{Codes, Specifications, and Standards}

Insufficient codes, specifications, and standards are barriers for engineers to choose appropriate design parameters for FRP composites. Some codes are available for design, but standard documents are still needed to address additional engineering judgements for composites. For instance, the ACI Committee 440 design guide currently used in the field will not cover everything in the broader construction ecosystem, and so developing specific guides that are directly related to individual applications was highly recommended. Consensus-based standards for durability assessments are lacking, and the long timeframe for consensus standard approval was found be an additional challenge. It was recognized that codes and standards set the designer's standard of care, and without a defined standard of care, to limit liability, designers will stay with traditional technologies. Earlier acceptance of FRP composites will result from development of application specific design guidance, not broad guidance. Furthermore, from a structural designer's point of view, the properties of FRP composites depend in complicated ways on their constituents (e.g., resin, fiber fractions and configuration) compared to the relative simplicity of conventional structural materials (e.g., steel), and this represents a FRP composite design challenge. 


\subsubsection{Procedures}

Insufficient FRP composites-specific construction procedures are barriers for designers since composites are relatively new materials to the civil engineering field. Education on the proper procedure for installation of FRP composite strengthening systems used for repair (e.g., a video for installation procedures) was recommended to facilitate installations in the field. Sharing construction history databases from the private sector in a usable way such as a web-based database, or establishing guidelines created by government entities (e.g., USDOT, Department of Homeland Security) was suggested. For instance, procedural information for joining and anchoring FRP composites to existing structures is insufficient for many engineers and technicians. Finally, inadequate information on both the shelf-life of component materials (e.g., resins) in FRP composites, as well as material health and safety data was also seen as a challenge.

\subsubsection{Quality Control}

Lack of specialized inspection technology of FRP composites during and after construction is a barrier. Methods of quality control of FRP composites during construction and the follow-up tests for assessing the material condition over time are limited, and many known methods for inspecting and assessing composites are difficult to perform in the field. It was suggested that structural health monitoring methods using easily implementable nondestructive or minimally invasive techniques be developed and used to evaluate the integrity of installed FRP composites.

\subsubsection{Overcoming the Top Barriers}

\subsubsection{Durability and Service Life}

End users, government, and academia were identified as a potential working group to investigate this barrier since each group has unique roles due to their different interests in durability and service life properties of FRP composites. During the discussion, participants (e.g., composites manufactures and designers) highlighted their interest in service life, environmental effects, and predictive models for FRP composites that can facilitate their structural design efforts. It was suggested that government, as a neutral party, compile durability data and define limits using codes and standards for the end user group. The group indicated that academia could be used to develop measurement methods and models.

\subsubsection{Training and Education}

Several suggestions such as including polymer material science courses in the civil engineering curriculum and continuing education courses were discussed, however, no specific actions were identified.

\subsubsection{Codes, Specifications, and Standards}

Government, academia and end user groups should tackle these issues together since each party has different roles in developing these documents. No specific action items were identified.

\subsection{Breakout Session 3: Stand-Alone Composites}

\subsubsection{Session Definition}

The participants defined stand-alone FRP composites as individual structural or equipment elements used in transportation, manufacturing, and infrastructure applications. Examples cited by the group included utility poles, marine pilings, modular or pre-fabricated FRP composite components that include bridge decks, tanks, pipes, ducts, stacks and gates, and 
roofing supports. The definition excluded structural elements such as reinforcement bars and FRP strengthening systems for concrete. Stand-alone FRP composite products are a small component of the overall FRP composites infrastructure market with unique challenges for increased market penetration. Owners, designers, and contactors are comfortable with traditional materials and construction methods and are therefore hesitant to use FRP composites despite their potential safety, life-cycle cost, and durability advantages. The key engineering design properties considered during the acquisition process are stiffness, failure strength, creep and creep rupture, damage tolerance, bearing strength, fatigue life, and environmental resistance (ultraviolet, temperature, solvent, salt). FRP composite materials have distinct material property advantages in one or more of these areas compared to traditional materials, especially in aggressive marine, high wind, and earthquake environments.

The group identified the top barriers for stand-alone FRP composite structures: (1) predicting service life; (2) codes, specifications, and standards; (3) first-cost paradigm; and (4) training and education. Specific challenges within each barrier category are discussed below.

\subsubsection{Predicting Service Life}

Typical service lifetimes for infrastructure structures range between 75 years to 125 years. ${ }^{5}$ Typical service environments include exposure to ultraviolet radiation, water/moisture, salt water, cyclic and sustained loads (fatigue), and wide temperature fluctuations. Durability and service life in realistic environments and time scales were identified by participants as the biggest challenges for FRP stand-alone structures. Manufacturers and users accept the superior durability of composite materials in harsh environments. The main challenge is the ability to quantify the remaining life for asset management purposes. For example, the corrosion rate or fatigue-crack propagation in steel is well understood and can be used to predict the likelihood of failure for a pipeline. In a FRP composite material, there may be no outward indicators of degradation or propagating cracks that allow accurate prediction of remaining service life. Further, these challenges can be broken down into three subcategories: safety factors, accurate prediction of service life, and accurate prediction of remaining service life.

\subsubsection{Safety Factors}

Currently, FRP structures are conservatively designed for safety (e.g., safety factors of 10:1 for corrosion, 2.5-4:1 on structural factors like creep), which increases cost and limits innovation in structural design. High safety factors are often used due to: lack of understanding of FRP materials (including their long-term durability), lack of accepted design standards, and lack of complete property characterization of a material.

\subsubsection{Accurate Prediction of Service Life}

Material property data gathered from realistic exposures is not widely available because many initial applications have not reached their estimated lifetime. Furthermore, a concerted effort has not been made to collect publicly available in-service data on changes in material properties with exposure. Many of the performance tests required for design are based on accelerated exposures, which result in a pass/fail criterion. This does not facilitate calculation of appropriate safety factors, or accurate failure predictions. In addition, these tests do not sufficiently account for interacting factors.

Examples of successful approaches for developing a framework of test methods, and predictive models for service-life are those established by the wind industry, with the National Renewable 
Energy Laboratory, ${ }^{6,7}$ and by the coatings industry, with NIST. ${ }^{8}$ Notably, these industries, in comparison with infrastructure, have expectations of much shorter desired service life and minimal maintenance. In addition, there are a multitude of FRP composites test methods developed through the aerospace and pressure vessel industries, but whether it is appropriate to use these methods to predict the service life for infrastructure applications is not clear. We acknowledge that the wind industry and coatings industry service life is much less than that for infrastructure, and usual expectations are for very minimal maintenance.

\subsubsection{Prediction of remaining service life}

There is a need to identify non-destructive monitoring methods coupled to statistical predictive modelling to facilitate accurate asset management decisions. This will continue to be a focus area for infrastructure applications as more communities shift to a resilience focus for their life-cycle support systems.

\subsubsection{Codes, Specifications, and Standards}

The group agreed that there is a lack of uniformity in design, manufacturing, certification, and inspection approaches for stand-alone FRP composites for infrastructure. Additional consensus based standards are needed, as are clearinghouses for data. Examples of data clearinghouses can be found for aerospace FRP composites, such as the Composite Materials Handbook 17 $(\mathrm{CMH}-17)^{9}$ and the Wichita State University NCAMP $^{10}$ databases. Nationally recognized codes and certification process documents are preferred over variable, region-specific practices.

\subsubsection{First-cost Paradigm}

Installed cost and short depreciation time limits do not accurately represent the cost advantages of FRP composites. However, reductions in material costs help to reduce installed cost, as was seen previously when FRP utility pole cross-arms came into widespread use after costs dropped.

\subsubsection{Training and Education}

Customers believe that FRP composite materials require onerous training and safety equipment for installation and maintenance. For example, trained installers are needed to repair infrastructure in the event of a natural disaster, which adds to the difficulty of deploying FRP composites outside of niche applications.

\subsubsection{Overcoming the Top Barriers \\ 3.3.6.1.Predicting Service Life}

Better material property data and test methods for accurate prediction of remaining service life would serve as a foundation to change safety factors in the existing codes and reduce the cost of FRP solutions. A survey and prioritization of measurement methods are required to clearly identify the path forward. Any identified test methods should be performance based and only material composition prescriptive as a last resort. The predictive modelling methods should be validated using a solid scientific framework, and should be developed in parallel with efforts aimed at the accurate prediction of service life.

\subsubsection{Codes, Specifications, and Standards}

The following codes/standards for stand-alone FRP composites, which serve as examples for future development activities were identified: 
- ASME RTP-1 Standard for Reinforced Thermoset Plastic Corrosion-Resistant Equipment ${ }^{11}$

- ASCE Pre-standard for Load and Resistance Factor Design (LRFD) of Pultruded FRP Structures ${ }^{12}$

- AASHTO Guide Specifications for the Design of FRP Pedestrian Bridges ${ }^{13}$

- ANSI/ACMA/FGMC FRP Composite Grating Manual for Pultruded and Molded Grating and Stair Treads ${ }^{14}$

The further development of these and other design standards related to the use of FRP composites for infrastructure applications will help owners become more comfortable with the specification of FRP composites. They will help engineers become more familiar with the use of FRP composites in designs, and will provide a more uniform approach to design with these materials. Although the development of standards such as these is a complicated task that takes significant time and commitment from numerous constituencies, the development of standards related to the use of FRP composites in infrastructure offers the opportunity to address numerous barriers that have been identified related to the adoption of FRP composites. Cooperation and coordination among industry, government, and academia is critical for the successful development and utilization of such standards.

The group recommended that the FRP community adopt a framework - comprised of manufacturing, quality control, and repair-process guides - supported by consensus standards. Areas needing improvement are standard methods of evaluating long term durability, and round robin testing in support of existing test methods and standards. A significant challenge with consensus standards is the time required to adopt a new standard and have it promulgated to users. Fig. 4 represents how manufacturers, material suppliers, maintainers, and installers intersect in a space governed by the new framework. The adopted consensus standards should also support the rapid acceptance of new matrix polymers, fibers, and manufacturing processes into infrastructure design, inspection, and regulation.

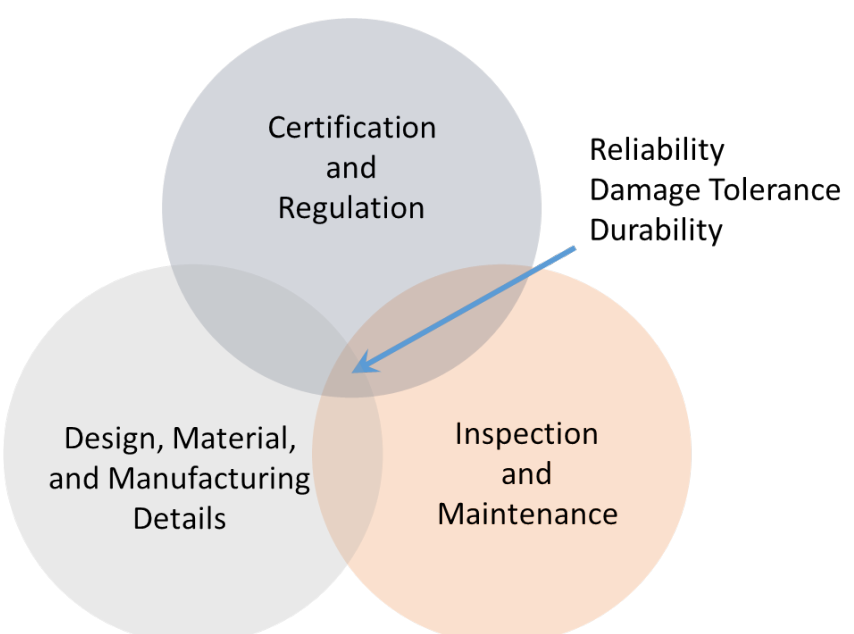

Fig. 4: Recommended framework for the FRP community. Attention to certification, design, and maintenance provides durability and cost effectiveness is necessary for sustainability. Courtesy Owens Corning. 


\section{Summary}

\subsection{Barriers to adoption of composites in infrastructure}

The workshop participants identified the cross-cutting barriers recognized by all breakout groups; these are shown in Table 1. The top three barriers were: Training and education, codes and standards, and durability and service life prediction. First cost was not viewed as a barrier in either the new construction, or the repair/retrofit construction breakout groups. However, the stand-alone FRP composites breakout group did call out first cost as a barrier, but did not see procedures and quality control as important issues.

Table 1: Matrix of cross-cutting barriers identified by each breakout group

\begin{tabular}{|l|c|c|c|}
\hline Cross-Cutting Barriers & New Construction & $\begin{array}{c}\text { Repair/Retrofit } \\
\text { Construction }\end{array}$ & $\begin{array}{c}\text { Stand-Alone } \\
\text { Composites }\end{array}$ \\
\hline Training/Education & YES & YES & YES \\
\hline Codes/Standards & YES & YES & YES \\
\hline Durability/Service Life & YES & YES & YES \\
\hline First Cost & NO & NO & YES \\
\hline Procedures & YES & YES & NO \\
\hline Quality Control & YES & YES & NO \\
\hline
\end{tabular}

The greatest impact can be obtained by focusing on the cross-cutting barriers, however there are barriers in individual applications that also need to be addressed. As an example, nondestructive inspection techniques need to be developed for locating composite rebar in new construction, to avoid damage during subsequent hole-making. Eliminating the cross-cutting barriers - with improved measurements, data, standards, specifications, training and predictive tools- will enable rapid commercialization of FRP composites for a more sustainable infrastructure.

\subsection{Roadmap}

The preliminary Roadmap in Fig. 5 is a primary product of this workshop; it is a strategic direction for future road mapping. The work to be done in overcoming barriers to the adoption of FRP composites in infrastructure has been divided into three activities or tasks: Durability Testing, Design Data Clearinghouse, and Education and Training. Each task was divided into several efforts with three overall goals in mind: Improved Costs and Sustainability, Widespread Adoption, and Trained Designers and Contractors. 


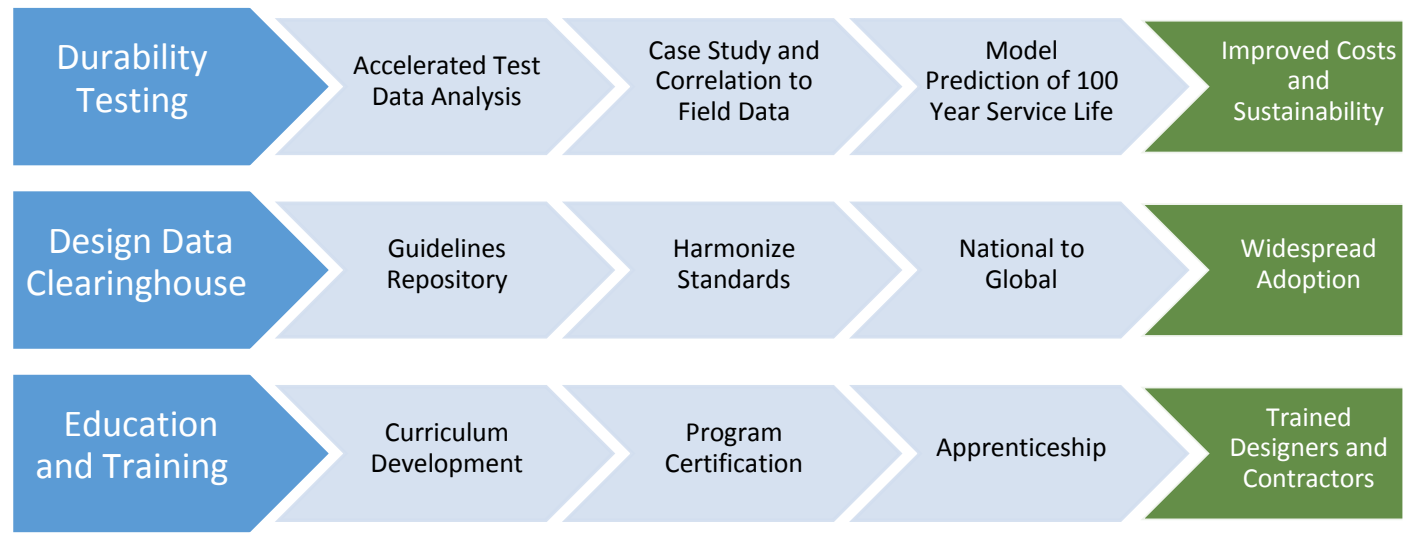

Fig. 5: Preliminary Roadmap designed during the workshop. This roadmap captures the nine basic efforts (center-section) that need to be completed to overcome the top three barriers (left-side) and achieve the three critical outcomes (right-side). Each effort may result in a workstream with multiple tasks and overlapping concerns.

\section{3. $\quad$ Durability Testing}

A five-year program is recommended to establish testbeds, gather data, and develop models from accelerated testing that would result in a set of reliable design tools. This empirical approach should be complimented by an a priori program focused on developing tools capable of predicting service life only from knowledge of the exact structure and combinations of materials. The resulting models and data would then become widely available to industry, endusers, engineers, architects, and designers through an on-line tool. Industry involvement is vitally important to ensure that the research program is commercially relevant, therefore a public-private partnership is envisioned. This partnership should focus on the collection of durability and service life information for composites as function of environmental and material parameters (ultraviolet, moisture, mechanical fatigue/creep, salt spray, freeze/thaw cycling, temperature exposure, chemical structure, etc.) using both case studies and laboratory testing to validate the predictions, ultimately targeting the ability to predict more than 100 years of service life. Of course, there will be different needs and expectations for FRP composites used in different regions, and different durability parameters may be more, or less, important in different applications.

The Durability Testing program should include:

- Identification of critical data and modeling needs

- Accelerated aging methods for FRP composites

- Fundamental durability and lifetime models

\subsection{Design Data Clearinghouse}

The participants collectively identified the need for a "clearinghouse" to gather, curate, and disseminate design guides and reliable data tables for infrastructure applications. This project would provide valuable data in the near term, by categorizing and storing existing information, specifically to make it widely available for infrastructure applications, and accessible to all 
stakeholders from standards bodies, to designers, to contractors. The Design Data Clearinghouse should seek to:

- Enable communication and education to end-users

- Enhance discoverability of FRP composite guides, methods, and standards

- Provide traceability and harmonization of standards and guidelines.

This clearinghouse should provide the initial progress towards the harmonization of design guidelines and standards so that a wider view of the design space and verification test methods are possible. This standardization, once proven at regional and eventually national scale, should be transitioned to a global effort to ensure a wide and uniform market, enabling widespread adoption of composites in infrastructure.

\subsection{Training and Education}

The information gathered or created from Durability Testing and Design Data Clearinghouse activities must be transferred to designers, practicing engineers, and end-users to be implemented in infrastructure applications. Curriculum development can incorporate the data and knowledge generated from these activities as they become available and accepted. These curricula can be utilized as requirements of a program certification effort by industry or standards organization stakeholders. Once such programs are created and recognized, they can serve as training for certified technicians and designers, who can train others in an apprenticeship for direct, decentralized, and personalized education of the necessary reserve of trained designers and contractors. 


\section{References}

[1] Bolin, CA, Smith, ST (2011) Life Cycle Assessment of PentachlorophenolTreated Wooden Utility Poles with Comparisons to Steel and Concrete Utility Poles. Renew. Sustain. Energy Rev 15(5):2475-2486. https://doi.org/10.1016/j.rser.2011.01.019

[2] Badgley L (2017) Infrastructure Report Card (American Society of Engineers, Reston, VA).

[3] Sparks, G, Christensen, P, Kostuk, K, Tadros, G (2008) Addressing Uncertainty and Complexity When Designing for Sustainability and Life Cycle Costs. 5th International Conference on Advanced Composite Materials in Bridges and Structures, Labossiere, P, Neale, KW, Eds. pp 121-131.

[4] Adams, T (2009) FY 2009 SRNL Hydrogen Delivery Project — Hydrogen Permeability and Pipeline Integrity/Fiber Reinforced Composite Pipeline. DOE Hydrogen Program 2009 Annual Progress Report. Section III.17, pp 358-360.

[5] (2009) AASHTO LRFD Bridge Design Guide Specifications for GFRPReinforced Concrete Bridge Decks and Traffic Railings, (American Association of State Highway and Transport Officials, Washington, DC), First Ed.

[6] Viselli, AM, Goupee, AJ, Dagher, HJ (2015) Model Test of a 1:8-Scale Floating Wind Turbine Offshore in the Gulf of Maine. J. Offshore Mech. Arct. Eng. 137(4):41901-41909.

[7] Jonkman, JM, Buhl Jr, ML (2005) FAST User's Guide (National Renewable Energy Laboratory (NREL), Golden, CO).

[8] Martin, JW, Saunders, SC, Floyd, FL, Wineburg, JP (1994) Methodologies for Predicting the Service Lives of Coating Systems (National Institute of Standards and Technolgy (NIST), Gaithersburg, MD).

[9] (2017) Composite Materials Handbook (CMH-17); (SAE International, Warrendale, PA).

[10] (2017) Wichita State University. National Center for Advanced Materials Performance. http://www.niar.wichita.edu/coe/ncamp.asp

[11] (2015) Reinforced Thermoset Plastic Corrosion Resistant Equipment (RTP-1) (American Society of Mechanical Engieners (ASME), New York, NY).

[12] Ellingwood, BR, Zureick, AH, GangaRao, HVS, Lopez-Anido, R, Bank, L (2010) Pre-Standard for Load \& Resistance Factor Design (LRFD) of Pultruded Fiber Reinforced Polymer (FRP) Structures (American Society of Civil Engineers, Reston, VA).

[13] (2008) Guide Specifications for Design of FRP Pedestrian Bridges, (American Association of State Highway and Transportation Officials (AASHTO), Washington, DC) First Ed.

[14] (2014) NSI/ACMA/FGMC FRP Composites Grating Manual For Pultruded and Molded Grating and Stair Treads, (American Composites Manufacturers Association (ACMA), Arlington, VA) First Ed. 


\section{Appendix A: Presentations}

\subsection{DeSimone}

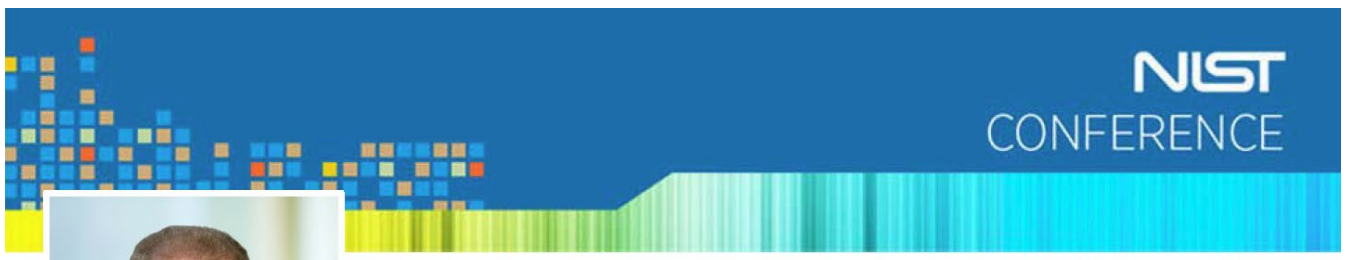

William R. O'Donnell, P.E.

Partner and Managing Principal

Desimone Consulting Engineers

Our Firm:

- Global Structural Engineering firm

- Over 10,000 projects worldwide

- Work in 45 countries, 40 states in the US.

- 300 Employees
My Responsibilities:

- Directly manage the Florida and California offices

- Firm-wide marketing

- Conceptual design

- Technical staff management

- Client contact

- General administration

- Collect money

\section{DESIMONE}

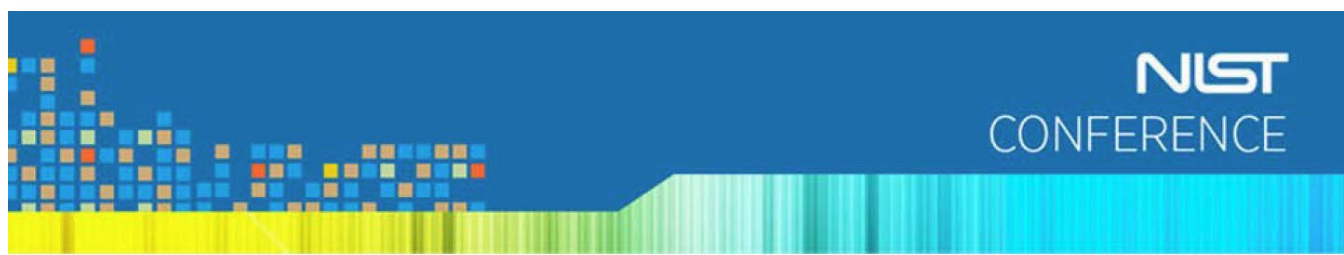

Top 5 Challenges We Face

1) Sourcing new work and new clients

2) Diversifying the practice with new markets and expanded geographical locations

3) Increased labor costs with downward fee pressure

4) Shortage of qualified US citizen engineers

5) High cost of litigation 


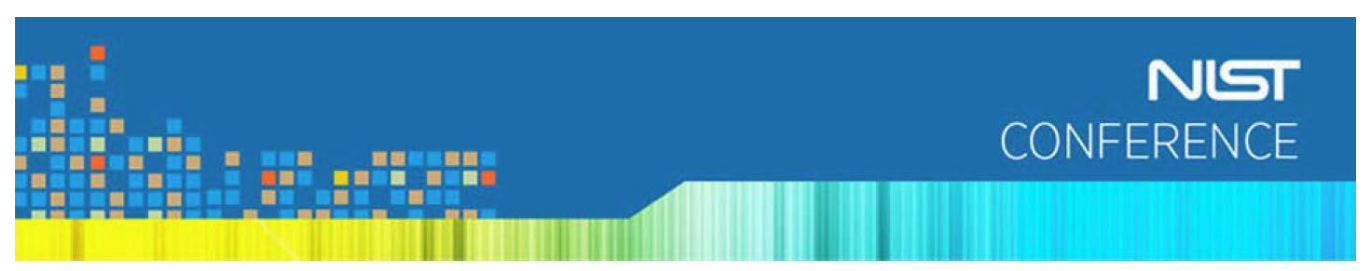

\section{Solutions}

1) Expansion into infrastructure

2) Provide multi-disciplinary engineering services

3) Promote engineering better in high school programs to increase talent pool

4) Consider ABET process. Make college level engineering curriculum more discipline specific. Current programs require a Master's degree candidate for entry level positions

5) Tort reform. Eliminate legalized extortion.

6) Better prediction on what President Trump will do next.

DESIMONE

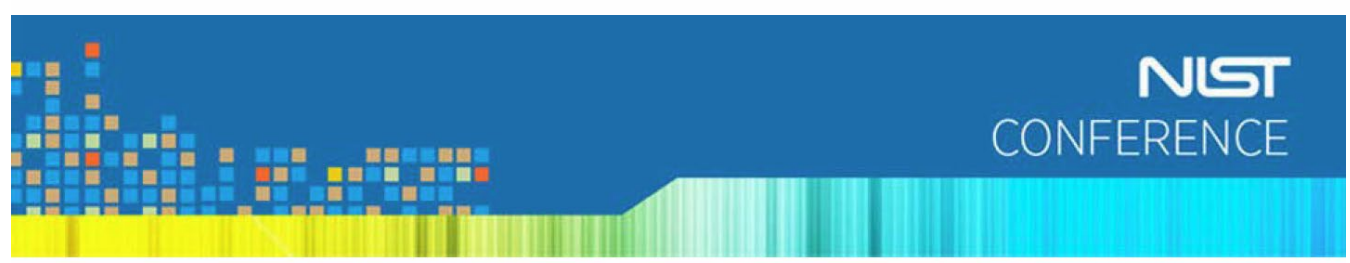

\section{Experience}

- Indian Ocean resort: FRP reinforcing bars

- Concrete restoration: Carbon fiber lamination

- Structural strengthening: Carbon fiber

\section{DESIMONE}




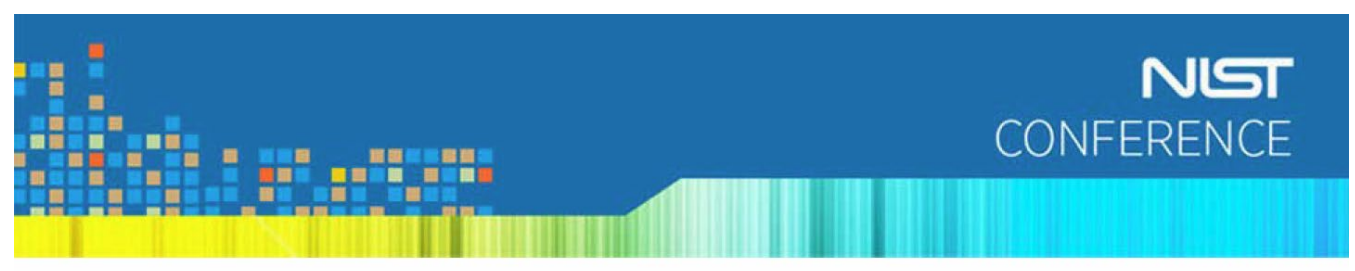

Optimal Application of Composite Materials

- Reinforcing coastal structures, especially in remote areas where quality concrete is not achievable

- Reinforcing structures subject to high levels of salt exposure

- Reinforcing coastal balconies

- Structural enhancement

- Structural repair

\section{DESIMONE}

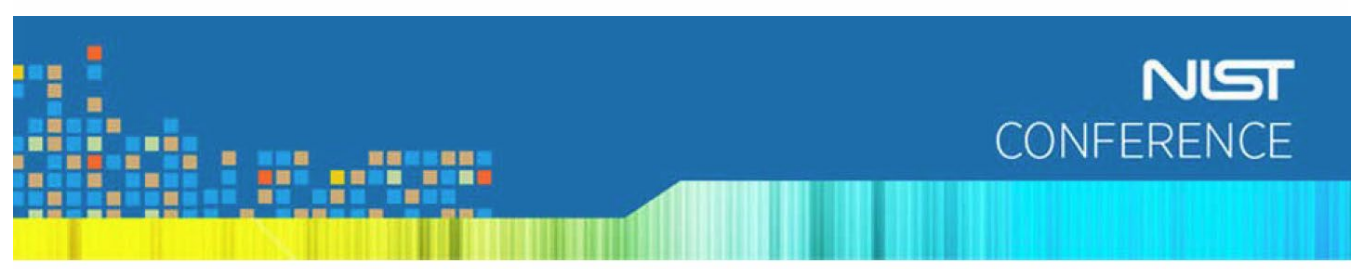

\section{Barriers to Adopting Composite Materials \\ - Lack of familiarity (Owner, Designer, and Contractor) \\ - Initial cost}




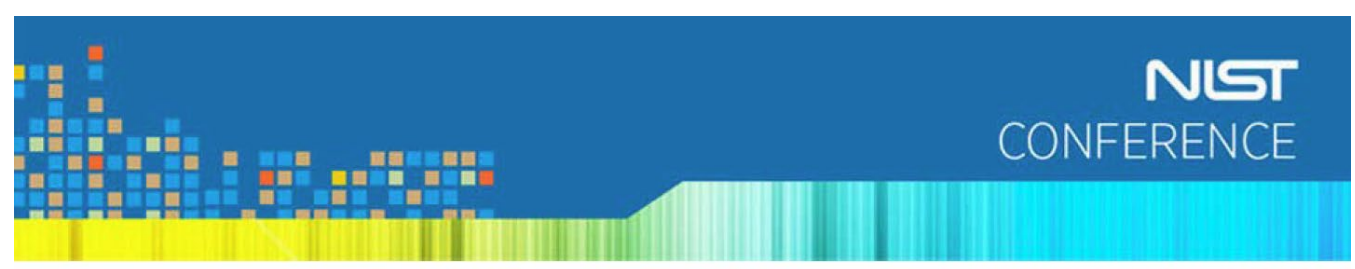

\section{Addressing the Barriers to Adoption}

- Greater saturation of technical seminars/workshops

- Manufacturers - direct presentations to engineers and contractors. Need emissaries.

- Initial and long term cost studies - will help with owner/developer buy-in

- Publish uniform design standards and specifications

- Establish reliable supply of material (quality and quantity)

DESIMONE 


\subsection{Simpson, Gumpertz, \& Heger Inc.}

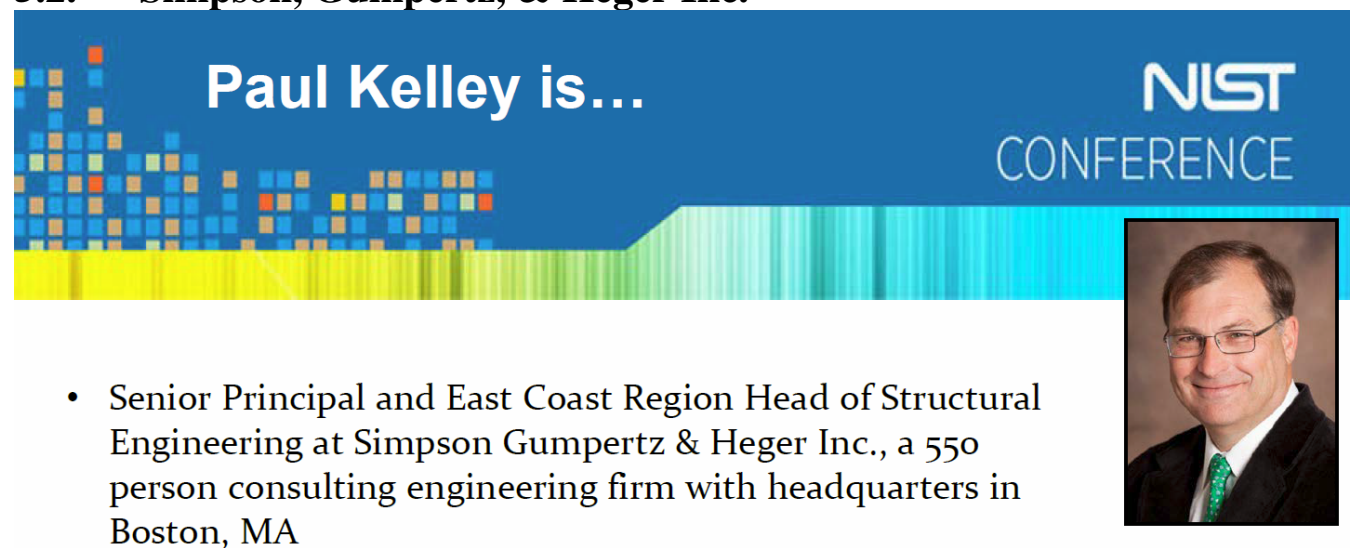

- Registered Engineer in MA, CT, NY, FL and many other states

- Experienced (at SGH 37 years) in structural design and structural repair

- Experienced in construction engineering and construction troubleshooting assignments for many large contractors

- Experienced in determining causes, damages, and costs of large complex insurance claims involving buildings and civil structures

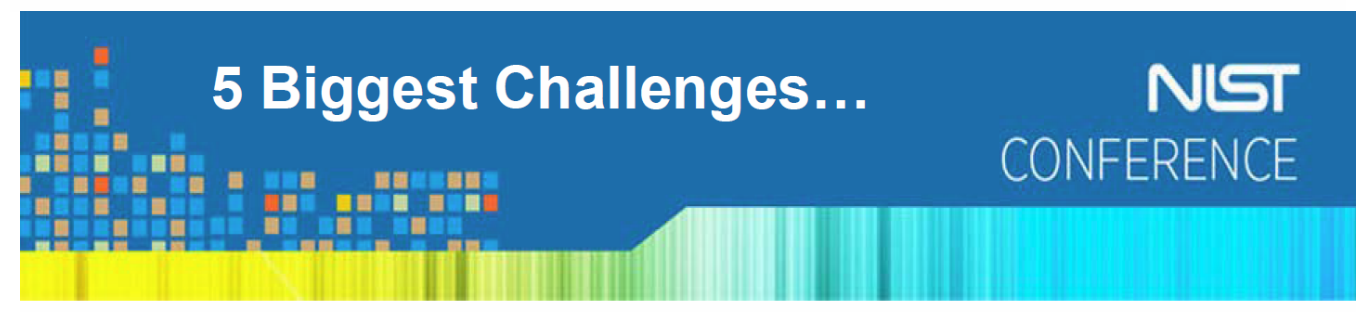

1. Finding non-commodity engineering assignments at reasonable fees that challenge high-performance staff

2. Creating new high-performance staff - recruiting, training, mentoring

3. Managing risk

4. Maintaining quality

5. Providing durable and sustainable designs 


\subsection{Caltrans}

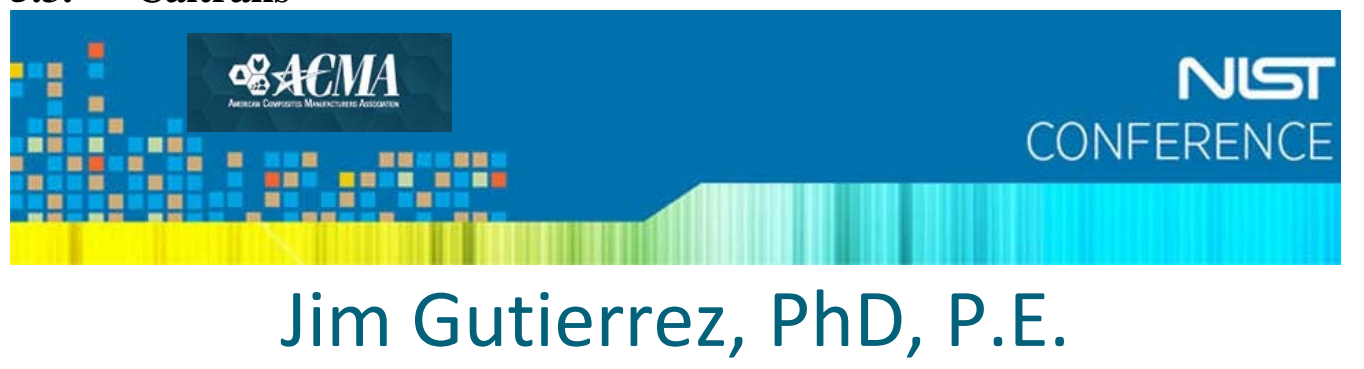

Senior Bridge Engineer, FRP Specialist

Office of Earthquake Engineering

Division of Engineering Services

California Department of Transportation (Caltrans)

Duties:

FRP Spec Development

FRP Design Guidance and Development

FRP Installation Inspection

FRP Performance Monitoring

Complex Numerical Modeling

Email

Jim.Gutierrez@dot.ca.gov

jgutierrez@csum.edu

\section{What solutions would address the challenges}

- Wide spread adoption of FRP:

Documentation of usage, and sharing lessons learned.

- Obtaining Durability Data:

Durability monitoring and Research

- High level of quality control in wet lay-up applications:

Pre-Construction Meetings reviewing Expectations and Experience Requirements

- Developing Design Guidance/Specifications:

AASHTO adoption, Material Specification Publication Database

- Obtaining Qualified Suppliers List \& Qualified Installers:

Standardized Prequalification Requirements 
What guidelines, standards, technology, or other developments for composites materials would address the barriers to adoption?

- AASHTO guide spec development and adoption

- Material Standardization

- Standardized inspection process/procedures

- Superior Bond/Standardized Anchorage details

- FRP Application Data Base

- Development of standard design equations.

- Development of NDE technology for FRP

Caltrans

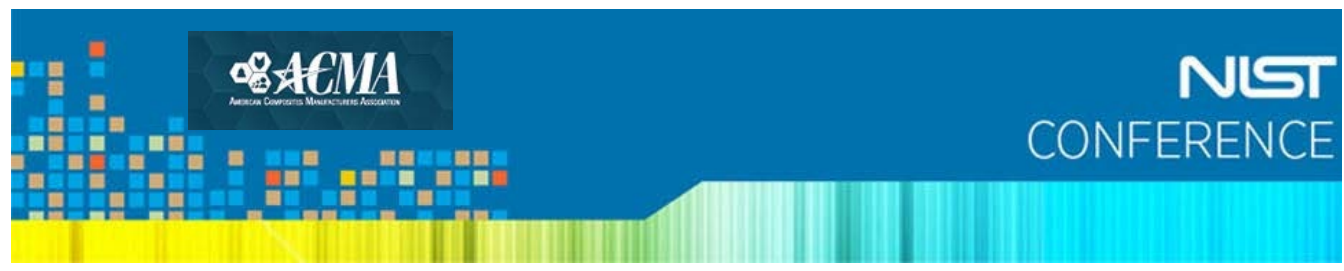

\section{Best applications for composite materials:}

- Strengthening Columns (non-bond critical)

- Strengthening: Beams/Girders, Arches, Pier Walls, Bent Caps, Decks

- NSM Strengthening

- FRP Reinforcement

- Prestressing with CFRP

- FRP Decks for special cases

- FRP Sign Post/Sign Structure 


\section{What are the 5 biggest challenges you face in your business/organization?}

- Not Qualified to speak on behalf of my organization

- Wide spread adoption of FRP

- Obtaining Durability Data

- High level of quality control in wet lay-up applications

- Developing Design Guidance/Specifications

- Obtaining Qualified Suppliers List \& Qualified Installers

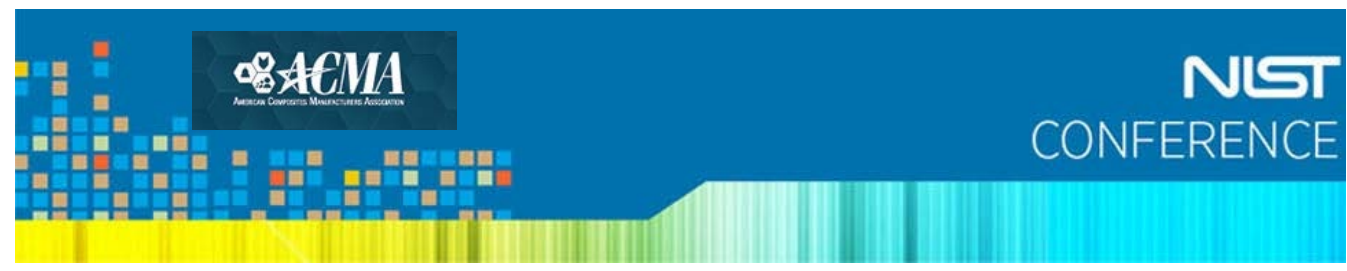

Experience with composites materials:

- Seismic Retrofit

- Flexural/Shear Strengthening: Columns, Beams/Girders, Bent Caps, Pier Walls, Arches, Decks, Deck Overhangs

- Repair: High Load Impact, FRP Deck Failure, Emergency Repair of Columns in Seismic Event

- FRP Composite Deck: Design, Performance Spec., Installation Inspection, Repair

- Near Surface Mounted (NSM), Strengthening using CFRP bar/rod

- Development Oversight of FRP Snap Locking Sign Structure. 


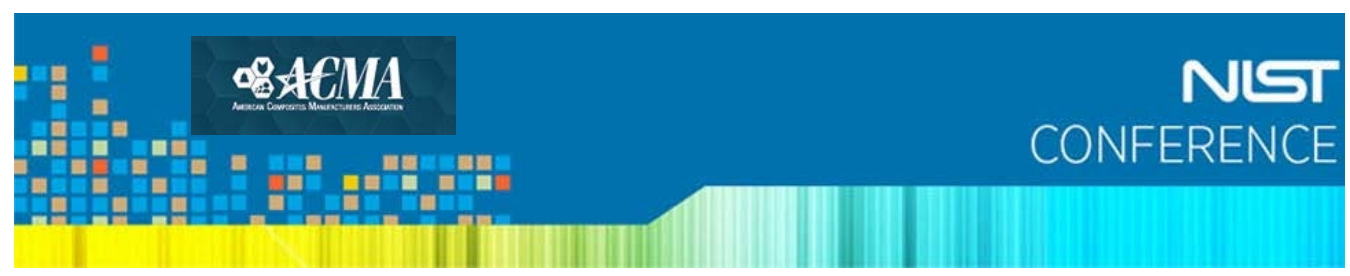

What guidelines, standards, technology, or other developments for composites materials would address the barriers to adoption?

- AASHTO guide spec development and adoption

- Material Standardization

- Standardized inspection process/procedures

- Superior Bond/Standardized Anchorage details

- FRP Application Data Base

- Development of standard design equations.

- Development of NDE technology for FRP

Caltrans 
5.4. NRECA

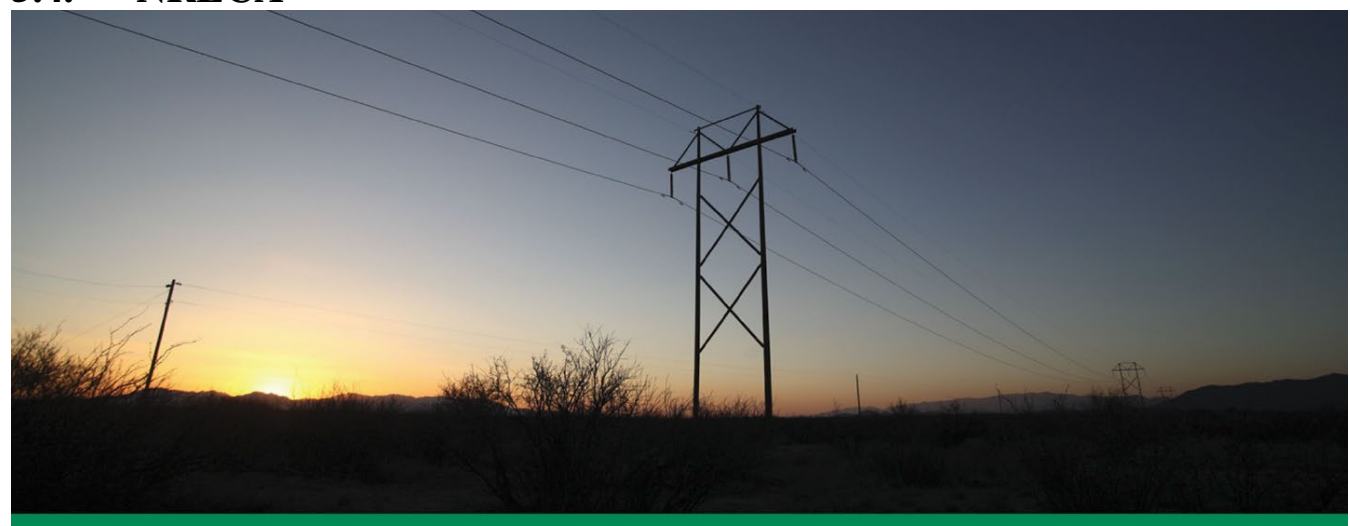

NIST Composites Workshop

February 9, 2017

Robert W. Harris, PE

Senior Principal, Transmission \& Distribution

Engineering

\section{NRECA Overview}

- Non-Profit Trade Association representing over 900 Member-Owned Rural Electric Cooperatives.

- Co-Ops own \& maintain 2.5 million miles (42\%) of the nation's electric distribution lines.

- Cover $3 / 4$ of the nation's landmass.

- Serve 18 million businesses, homes, farms, schools in 2,500 of the nation's 3,141 counties. 


\section{Million Members in 47 States}
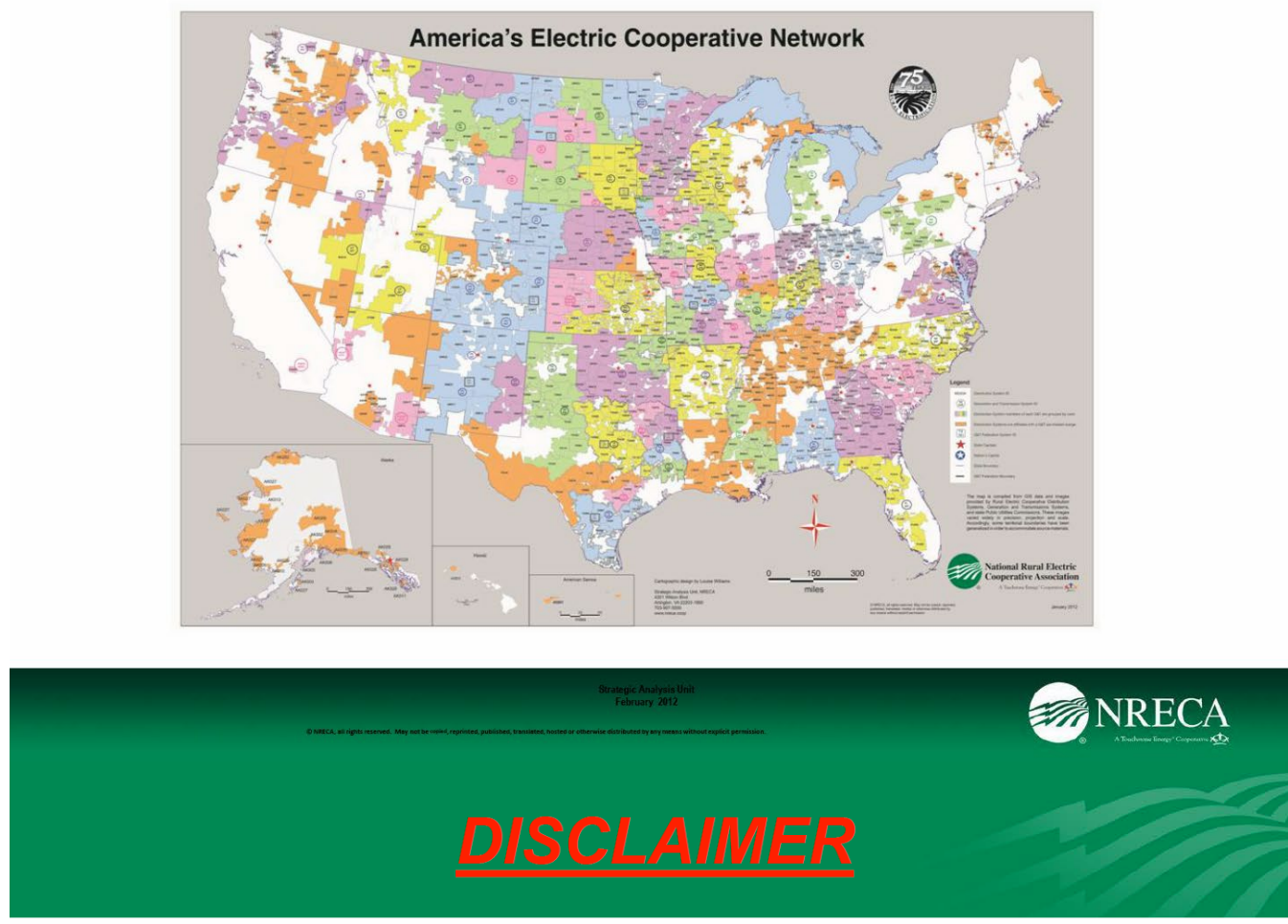

- Wood Quality Control Inc, is a Subsidiary of NRECA.

- Wood Pole \& Crossarm Inspection Program.

- Inspection of Products (both In-Plant and At-Destination).

- Approval of Plants.

- Created at the request of RUS in 1982.

- Operates At Cost + Margins.

- https://www.cooperative.com/public/wqc/about/Pages/default.aspx 


\section{Poles}

- Co-Ops Use from 400,000 - 700,000 poles/year.

- $\sim 95 \%$ are Distribution Class (<=50').

- Nearly all are wood.

- Steel \& concrete used extensively in transmission.

- New construction w/composites would likely not be an issue, but...

\section{DNRECA}

\section{Storm Damage}

- Massive capacity to produce \& deliver wood poles60,000 delivered in a matter of weeks following Sandy.

- Mutual Aid agreements between Co-Ops across state lines allow rapid mobilization of work force for storm related restoration.

- All Co-Op linemen \& contractors know how to work with wood. Composites...?

- No time to train or instruct for storm conditions.

- QC of work?

- Still have to climb in many cases. 


\section{Pros}

- Light weight.

- Modular design- allows flexibility in stocking.

- Dielectric material (as opposed to steel or concrete).

- Crossarms gaining greater acceptance.

- Flexibility may reduce risk of breaking.

\section{Concerns}

- Impact performance (i.e., cars \& trucks).

- UV degradation.

- Drilling- bits \& dust (masks?).

- Over-tightening bolts- no damage to wood poles. Will composites crack? Effect on strength?

- For climbing- positioning on pole (similar to steel \& concrete)

- Some Flexibility is good, but how flexibly are they?

- Stated life of 60-80 years- assume based on accelerated aging. Comparison to actual experience with wood?

- Disposal and/or recycling. 


\section{Barriers to Composites}

- Composite poles seen as a niche product.

- Initial cost.

- Resiliency- Poles are only one component.

- Enormous experience with wood:

- Flexible

- Widely available

- Generally easy to handle \& work with

- Not experiencing significant problems w/wood. 


\title{
5.5. Astaldi
}

National Institute of Standards and Technology

\section{ASTALDI Astaldi Construction Corporation}

\author{
Astaldi Construction Corporation is the US Subsidiary of Astaldi SpA (www.astaldi.com), \\ leading general contractor and one of the major players worldwide. \\ The Group has been listed on the Stock Exchange since 2002, and holds 92nd place in \\ the worldwide rankings of Contractors. It closed the 2015 financial year with a total \\ order backlog, including additional projects secured and being finalized, equal to more \\ than EUR 28 billion and EUR 2.9 billion in revenue, and is active with about 11,000 \\ employees worldwide. \\ Today, Astaldi contributes to the development of 6 macro-areas in the world: Italy, \\ Central Europe (Poland, Romania, Russia) and Turkey, the Middle East (Saudi Arabia) and \\ the Far East (Indonesia), the Maghreb (Algeria), Latin America (Venezuela, Peru, Chile, \\ Central America) and North America (Canada, USA). It has a keen eye on the \\ opportunities in new areas of development, like Cuba, Vietnam, Iran, and Indonesia.
}

\section{National Institute of Standards and Technology \\ ASTALD I \\ Challenges}

- Competitive market - todays market is increasingly compensative, making it difficult for contractors to win projects and make profits.

- Use of polymer composites in infrastructure applications, whist beneficial for the Client, is still expensive for a Contractor to propose for a any specific project.

- Polymer composites - important lead time require companies to carefully schedule materials and monitore production to avoid delays.

- Polymer composites - contractors are required to procure additional quantities of RFP as a contingency for against damages to rebar's during installation.

- Training - additional training site personnel and logistics to ensure correct placing. 


\section{Solutions}

- Material costs - reduction in material costs which would allow polymer composites to be appealing to Contractors. Whilst transportation and placing of FRP are cheaper with respect that traditional black steel rebars, the material costs, site logistics, lifting plans, precautions required during rebar fixing and concreting make the product economically unattractive to Contractors.

- Reduction in lead time for manufacturing special formed shapes would make polymer composites manageable for construction sites.

- Reduction in procurement and delivery times will reduce the need of additional mitigation quantities.

- Special splicing details and fixing of bars would reduce time for preparation of rebar cages and placing and mitigate.

\section{National Institute of Standards and Technology}

\section{Experience with FRP}

More than 20 years using FRP:

\begin{tabular}{|l|l|}
\hline \multicolumn{2}{|c|}{ Astaldi's Recent Projects using FRP } \\
\hline $\begin{array}{l}\text { Metro Copenhagen,Phase 1 \& } \\
\text { 2 - Denmark }\end{array}$ & $\begin{array}{l}\text { Metro Milan Line 5 Bignami - } \\
\text { Garibaldi, Italy }\end{array}$ \\
\hline Metro Brescia. Italy & $\begin{array}{l}\text { Metro Naples Line 1, Piscinola } \\
\text { - Centro Direzionale, Italy }\end{array}$ \\
\hline Metro Genoa, Italy & $\begin{array}{l}\text { Metro Rome Line C, Italy } \\
\text { Phase 1 and Phase 2 }\end{array}$ \\
\hline Metro Milan Line 4, Italy & Metro Warsaw, Poland \\
\hline $\begin{array}{l}\text { Metro Milan Line 5, San Siro - } \\
\text { Garibaldi, Italy }\end{array}$ & Rome-Naples HSR, Italy \\
\hline
\end{tabular}

Astaldi's use of FRP, has been predominately for mechanized tunneling, and NATM works. 


\section{FRP in Tunneling}

- Use of 'Soft Eye' in breakthroughs of Tunnel Boring Machines (TBMs) in stations/shafts.

- Use of Glass FRP reinforcements for tunnel face strengthening in soft ground NATM tunnels works.
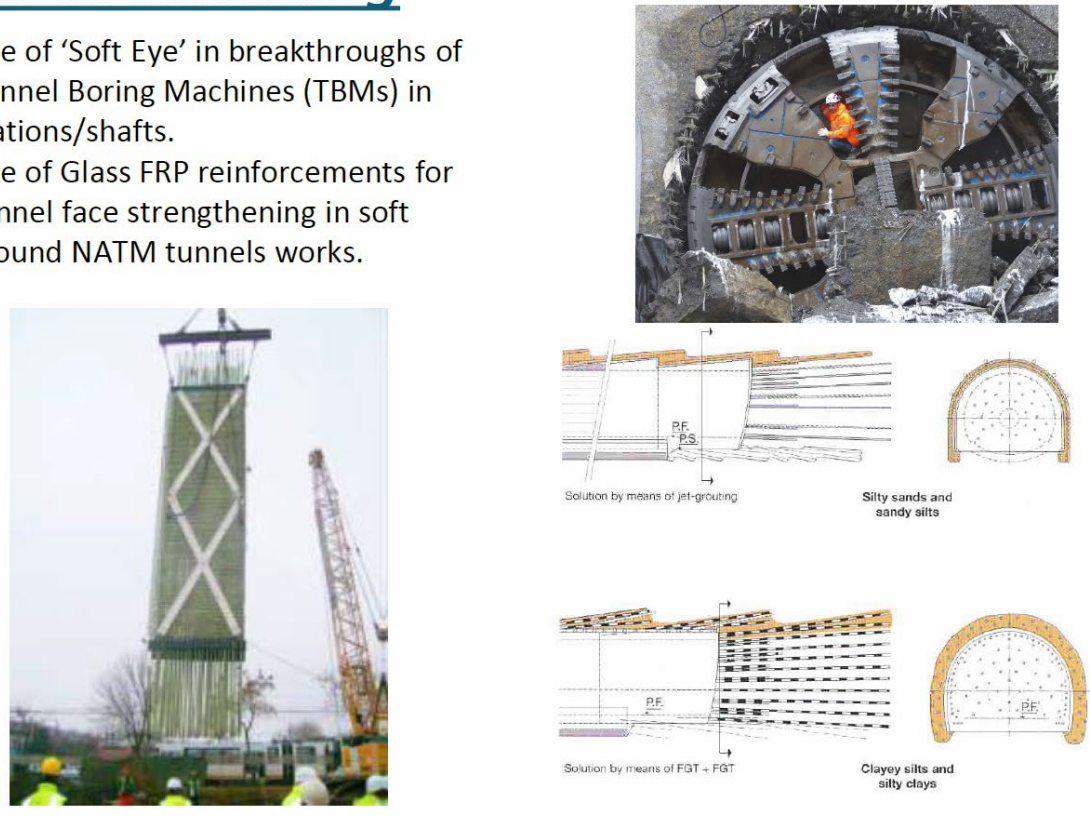

National Institute of Standards and Technology

\section{$\underline{F R}$ in Permanent Works}

ASTALDI

In recent years, the improvement in materials and testing have allowed FRP to make the jump from 'temporary works' to 'permanent works'.
$>$ Concrete Tunnel Linings/Segments with FRP.

$>$ LRT Track Beds - Mitigation of Stray Current Corrosion

$>$ Reinforced Concrete Structures in marine environments.

$>$ Reinforced Structures subject to harsh environment - cold weather climates.
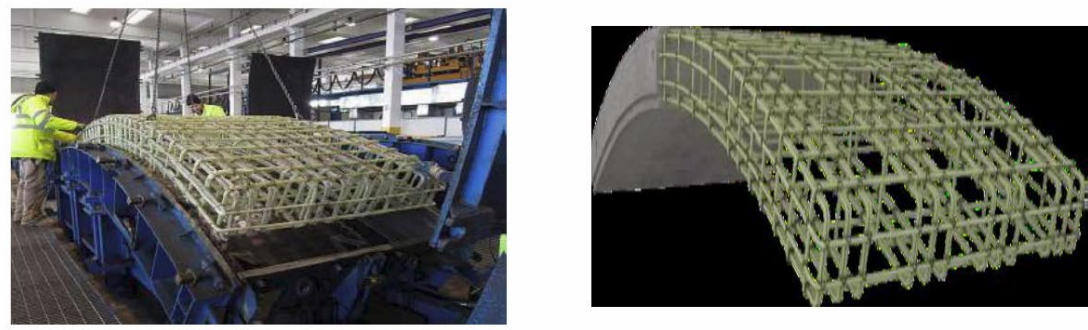


\section{Best applications for composite materials}

- Tunnel construction - mechanized and traditional

- Concrete Tunnel Linings/Segments with FRP.

- LRT Track Beds - Mitigation of Stray Current Corrosion

- Reinforced Concrete Structures in marine environments.

- Reinforced Structures subject to harsh environment cold weather climates.

- Reinforced Structures in aggressive environmental conditions. 


\section{Appendix B: Agenda}
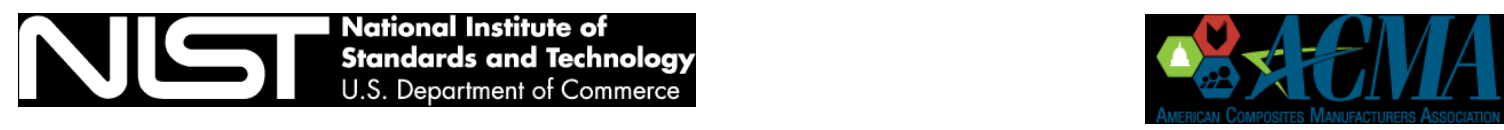

\section{Road Mapping Workshop on Overcoming Barriers to Adoption of Composites in Sustainable Infrastructure}

February 8-9, 2017

National Institute of Standards and Technology 100 Bureau Drive, Gaithersburg, MD, 20899-8542

Room: BLDG 215, C103-C105

\section{AGENDA}

\begin{tabular}{|c|c|c|}
\hline \multicolumn{3}{|c|}{ Wednesday - February 8, 2017} \\
\hline Time & Subject & Discussion Lead \\
\hline $12: 30 \mathrm{pm}$ & $\begin{array}{l}\text { Arrive at NIST } \\
\text { Process through security }\end{array}$ & Group \\
\hline 1:00 pm & $\begin{array}{l}\text { Welcome } \\
\text { 1. Workshop Overview } \\
\text { a. Why are we here? } \\
\text { b. Standards for a sustainable } \\
\text { infrastructure? } \\
\text { c. Purpose, Scope, and Deliverables of the } \\
\text { 2. Self-introductions }\end{array}$ & Jeff Gilman, NIST (workshop leader) \\
\hline $1: 45 \mathrm{pm}$ & $\begin{array}{l}\text { Background Presentations on Needs } \\
\text { 1. Designers Perspective } \\
\text { a. Repair/Retrofit Construction } \\
\text { b. New Construction } \\
\text { 2. Owners Perspective }\end{array}$ & $\begin{array}{l}\text { John Busel, ACMA (moderator) } \\
\text { 1. Paul Kelley PE, SGH } \\
\text { William O'Donnell, PE, DeSimone } \\
\text { 2. Jim Gutierrez, PE, Caltrans }\end{array}$ \\
\hline $2: 45 \mathrm{pm}$ & Supply Chain Perspective on Needs & Group \\
\hline $3: 15 \mathrm{pm}$ & BREAK & Group \\
\hline $3: 30 \mathrm{pm}$ & $\begin{array}{l}\text { Breakout Group Instructions and Process } \\
\text { Group A - New Construction } \\
\text { Group B - Repair/Retrofit Construction } \\
\text { Group C - FRP Stand-alone Structures } \\
\text { 1. Group Assignments (handout) } \\
\text { 2. Facilitator, note taker (handout) } \\
\text { 3. Discussion Questions (handout) } \\
\text { 4. } \text { Report to Group on Day } 2 \text { - format }\end{array}$ & $\begin{array}{l}\text { Jeff Gilman, NIST } \\
\text { John Busel, } A C M A\end{array}$ \\
\hline $3: 45 \mathrm{pm}$ & $\begin{array}{l}\text { Breakout Group Discussion - identify the issues, } \\
\text { concerns, and other barriers to adoption of composite } \\
\text { materials and products including but not limited to } \\
\text { composites rebar, decking, repair, utility poles, storage } \\
\text { tanks, pilings, dams, and building cladding. }\end{array}$ & $\begin{array}{l}\text { Group A - Building 215, Room C103-C105 } \\
\text { Group B - Building 217, Room H107 } \\
\text { Group C - Building 217, Room H103 }\end{array}$ \\
\hline $5: 15 \mathrm{pm}$ & Adjourn for Day & $\begin{array}{l}\text { Marriott Shuttle Bus } \\
\text { ACMA Delegates Shuttle Bus }\end{array}$ \\
\hline $5: 45 \mathrm{pm}$ & $\begin{array}{l}\text { Reception at Gaithersburg Marriott Washingtonian } \\
\text { Center, } 9751 \text { Washingtonian Boulevard }\end{array}$ & \\
\hline 7:00 pm & $\begin{array}{l}\text { Dinner on your own (restaurants recommended } \\
\text { by NIST) } \\
\text { - ACMA Industry Delegates Shuttle Bus to Hotel }\end{array}$ & \\
\hline
\end{tabular}




\section{NG}

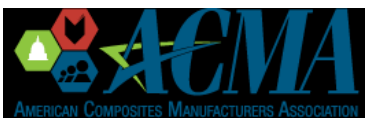

\begin{tabular}{|c|c|c|}
\hline \multicolumn{3}{|c|}{ Thursday - February 9, 2017} \\
\hline Time & Subject & Discussion Lead \\
\hline $8: 30 \mathrm{am}$ & $\begin{array}{l}\text { Arrive at NIST } \\
\text { Process through security }\end{array}$ & Group \\
\hline $8: 45 \mathrm{am}$ & Day 2 Start - Overview & Jeff Gilman, NIST (workshop leader) \\
\hline 9:00 am & $\begin{array}{l}\text { Breakout Group Discussion - identify the cross-cutting } \\
\text { metrology needs (the science of experimental and } \\
\text { theoretical measurement) such as improved measurements, } \\
\text { data, standards and specifications, and predictive tools to } \\
\text { model service life and performance that would enable more } \\
\text { rapid commercialization of composites for a sustainable } \\
\text { infrastructure }\end{array}$ & $\begin{array}{l}\text { Group A - Building 215, Room C103-C105 } \\
\text { Group B - Building 217, Room H107 } \\
\text { Group C - Building 217, Room H103 }\end{array}$ \\
\hline $10: 45 \mathrm{am}$ & BREAK & Group \\
\hline $11: 00 \mathrm{am}$ & $\begin{aligned} \text { Breakout Group Reports } \\
\text { 1. } \\
\text { 2. Group A - New Construction } \\
\text { 3. } \text { Group C - Repair/Retrofit Construction } \\
\end{aligned}$ & $\begin{array}{l}\text { Group A Facilitator } \\
\text { Group B Facilitator } \\
\text { Group C Facilitator }\end{array}$ \\
\hline $12: 00 \mathrm{pm}$ & LUNCH & Group \\
\hline $1: 00 \mathrm{pm}$ & $\begin{aligned} & \text { Wrap-up } \\
& \text { 1. } \text { Summary } \\
& \text { 2. } \text { Final Group Comments } \\
& \text { 3. } \text { Next Steps }\end{aligned}$ & $\begin{array}{l}\text { Jeff Gilman, John Busel } \\
\text { Group } \\
\text { Jeff Gilman, John Busel }\end{array}$ \\
\hline $2: 00 \mathrm{pm}$ & $\begin{array}{l}\text { Adjourn } \\
\text { Group departs for home }\end{array}$ & Jeff Gilman \\
\hline
\end{tabular}




\section{Appendix C: Attendees}

\begin{tabular}{|c|c|c|}
\hline First Name & Last Name & Organization \\
\hline John & Amonett & Owens Corning \\
\hline Mark & Aubart & Arkema Inc \\
\hline Jeff & Austad & Magnum Venus Products \\
\hline Charles & Bakis & Pennsylvania State University \\
\hline Bryan & Barragan & Owens Corning \\
\hline Janice Paige & Buchanan & USACE ERDC \\
\hline John & Busel & American Composites Manufacturers Association (ACMA) \\
\hline Robert & Combs & CIS Precision Epoxies \\
\hline Daniel & Coughlin & American Composites Manufacturers Association (ACMA) \\
\hline James & Crain & Composites One LLC \\
\hline Ravi & Deo & Engineering Management Business Relations (EMBR) \\
\hline Mohammad & Ehsani & QuakeWrap, Inc. \\
\hline Howard & Elliott & RS Technologies Inc. \\
\hline James & Fekete & National Institute of Standards and Technology (NIST) \\
\hline Chiara & Ferraris & National Institute of Standards and Technology (NIST) \\
\hline Aaron & Forster & National Institute of Standards and Technology (NIST) \\
\hline Amanda & Forster & National Institute of Standards and Technology (NIST) \\
\hline Joseph & Fox & Ashland Performance Materials \\
\hline Jeffrey & Gilman & NIST - Materials Science and Engineering Division \\
\hline Mike & Gordon & Gordon Development \\
\hline Bradley & Grainger & RS Technologies Inc. \\
\hline Trevor & Gundberg & Vectorply Corporation \\
\hline $\mathrm{Jim}$ & Gutierrez & California Department of Transportation (Caltrans) \\
\hline Robert & Harris & National Rural Electric Cooperative Association (NRECA) \\
\hline David & Hartman & Owens Corning \\
\hline John & Hausfeld & Baker Concrete Construction Inc. \\
\hline Joe & Hedger & Magnum Venus Products \\
\hline Gale & Holmes & National Institute of Standards and Technology (NIST) \\
\hline Scott & Holmes & Highland Composites \\
\hline Donald & Hunston & National Institute of Standards and Technology (NIST) \\
\hline Paul & Kelley & Simpson Gumpertz \& Heger Inc. \\
\hline Jae Hyun & Kim & National Institute of Standards and Technology (NIST) \\
\hline $\operatorname{lan}$ & Kopp & Kenway Corporation \\
\hline Ajay & Krishnamurthy & National Institute of Standards and Technology (NIST) \\
\hline Ellen & Lackey & University of Mississippi \\
\hline Ray & Liang & Center for Integration of Composites into Infrastructure \\
\hline Vinay & Mishra & DIXIE CHEMICAL \\
\hline Robert & Moser & US Army Engineer Research and Development Center \\
\hline Derek & Muir & Hill \& Smith Holdings PLC \\
\hline
\end{tabular}




\begin{tabular}{|c|c|c|}
\hline First Name & Last Name & Organization \\
\hline Antonio & Nanni & University of Miami \\
\hline Bharath & Natarajan & National Institute of Standards and Technology (NIST) \\
\hline Norris & Nicholson & USDA Rural Utilities Service \\
\hline William & O'Donnell & DeSimone Consulting Engineers \\
\hline Richard & Pauer & Polynt Composites US \\
\hline Dayakar & Penumadu & University of Tennessee \\
\hline Srinivasan & Rajagopalan & ExxonMobil Research and Engineering Company \\
\hline Scott & Reeve & Composite Advantage \\
\hline Jean-Pascal & Schroeder & Scott Bader \\
\hline Timothy & Shaffer & ExxonMobil Research and Engineering Company \\
\hline Richard & Sheridan & Northwestern University \\
\hline Dustin & Troutman & Creative Pultrusions, Inc. \\
\hline Timothy & Truster & University of Tennessee \\
\hline George (Alan) & Vaughan & ExxonMobil Chemical Company \\
\hline Mikhail & Vorobev & Owens Corning \\
\hline Stephanie & Watson & National Institute of Standards and Technology (NIST) \\
\hline Shane & Weyant & Creative Pultrusions, Inc. \\
\hline David & White & Sika Corporation \\
\hline Chuck & Zhang & Georgia Institute of Technology \\
\hline
\end{tabular}

\section{Appendix D: Additional Material}

Complete PDFs of the keynote presentations in a ZIP archive file are available at https://doi.org/10.6028/NIST.SP.1218s. 